
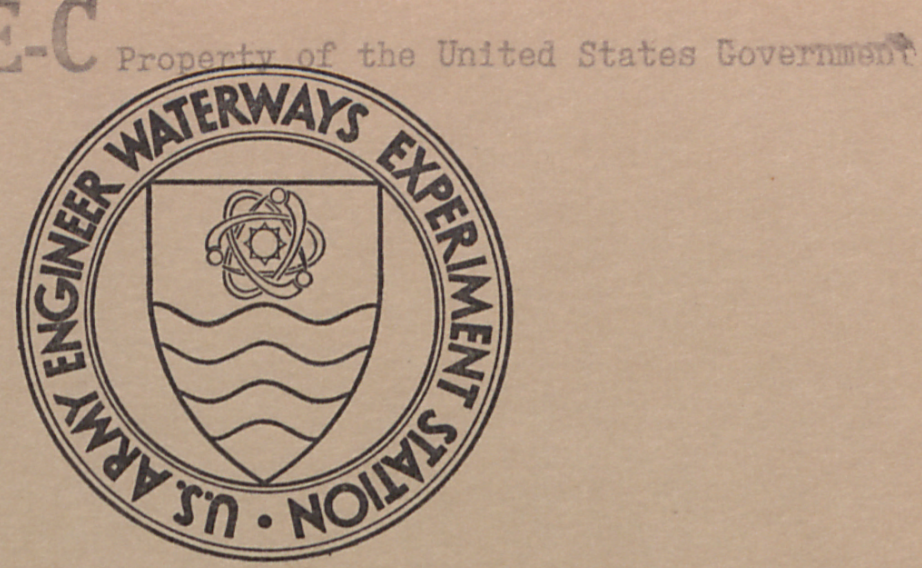

MISCELLANEOUS PAPER S-73-56

\title{
LATERAL DISTRIBUTION OF AIRCRAFT TRAFFIC
}

by

D. N. Brown, O. O. Thompson
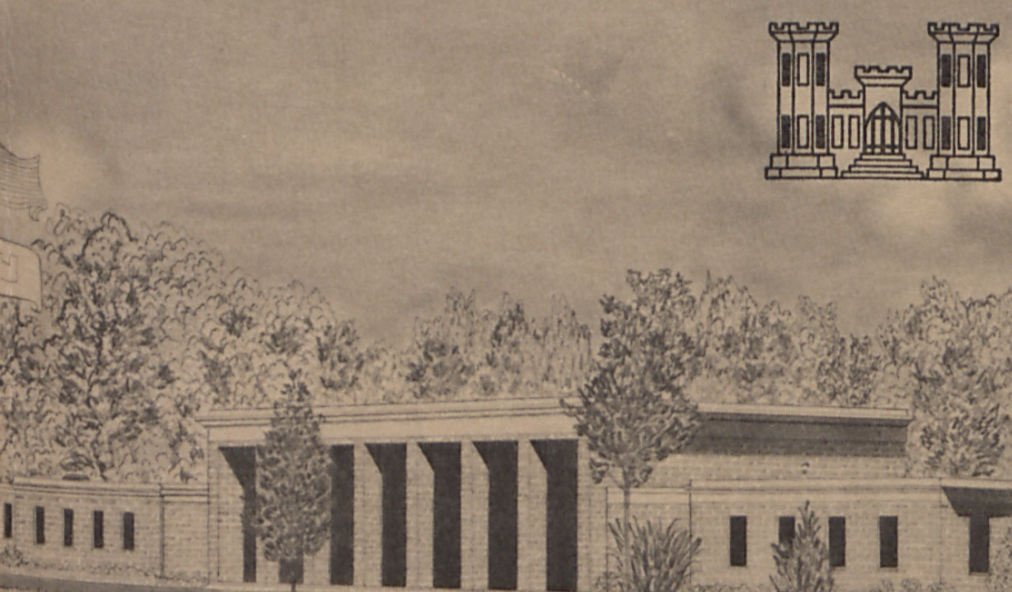

\section{US ARMY ENGINEER WATERWAYS EXPERIMENT STAWLN \\ July 1973}

LIBRARY BRANCH
TECHNICAL INFORMATION CE
ENGINEER WATERWAYS EXPER
YICKSBURG. MISSISSIPPA

UIBRARY BRANCH
TECHNICAL INFORMATION CENTER
ENGINEER WATERWAYS EXPERIMENT
YICKSBURG. MISSISSIPPA

Sponsored by Office, Chief of Engineers, U. S. Army

Conducted by U. S. Army Engineer Waterways Experiment Station

Soils and Pavements Laboratory

Vicksburg, Mississippi 


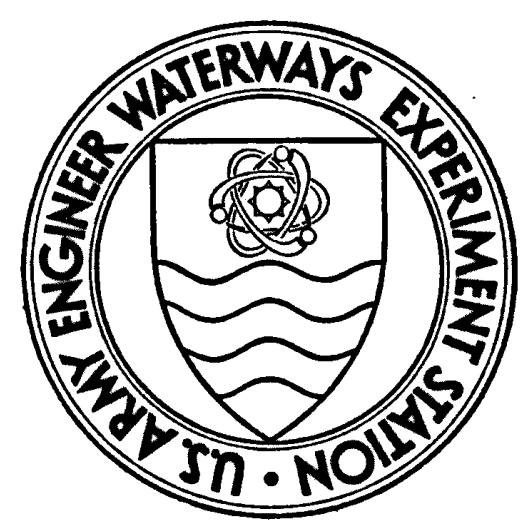

MISCELLANEOUS PAPER S-73-56

\title{
LATERAL DISTRIBUTION OF AIRCRAFT TRAFFIC
}

\author{
by \\ D. N. Brown, O. O. Thompson
}

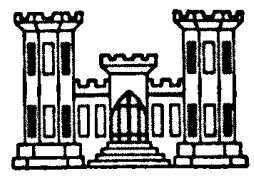

July 1973

Sponsored by Office, Chief of Engineers, U. S. Army

Conducted by U. S. Army Engineer Waterways Experiment Station

Soils and Pavements Laboratory

Vicksburg, Mississippi 
FOREWORD

The study reported herein was sponsored by the U. S. Army Military Engineering Design and Expedient Construction Criteria (MEDECC) Program, Task 02, Work Unit 002, Evaluation of Existing Airfields for C-5A Operations.

This study was conducted under the overall supervision of Messrs. J. P. Sale, R. L. Hutchinson, R. G. Ahlvin, and D. N. Brown, Soils and Pavements Laboratory, U. S. Army Engineer Waterways Experiment Station (WES). The study was conducted by Dr. 0. O. Thompson and Mr. D. N. Brown during the period June 1970-July 1971. This report was written by $\mathrm{Dr}$. Thompson and $\mathrm{Mr}$. Brown.

COI Ernest D. Peixotto, CE, was Director of WES during the conduct of this study and preparation of this report. Mr. F. R. Brown was Technical Director. 
CONTENTS

$\underline{\text { Page }}$

FOREWORD ...................... . .

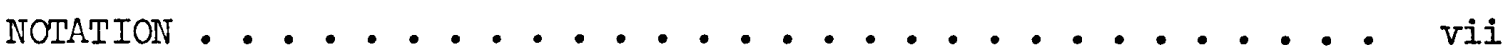

CONVERSION FACTORS, BRITISH TO METRIC UNITS OF MEASUREMENT . . . ix

SUMMARY ............................... xi

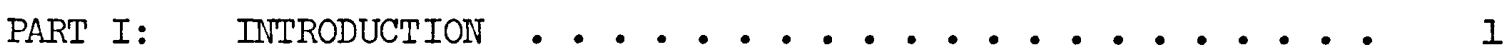

PART II: THE DEVELOPMENT OF THE CURRENT PASS/COVERAGE RATIO • • 3

Historical Background ............... 3

Discussion of Operation Levels . . . . . . . . . 16

PART III: DEVELOPMENT OF REVISED TRAFFIC DISTRIBUTION CONCEPTS • 18

PART IV: COMPARISON OF METHODS OF DETERMINING PASS/COVERAGE

VALUES .......................... 30

PART V: CONCLUSIONS AND RECOMMENDATIONS ......... 36

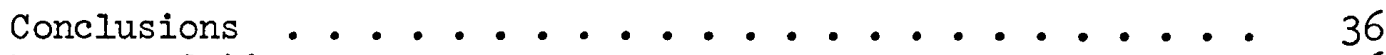

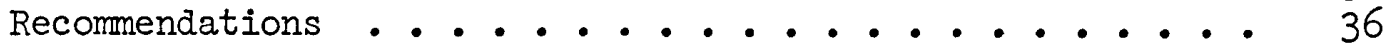

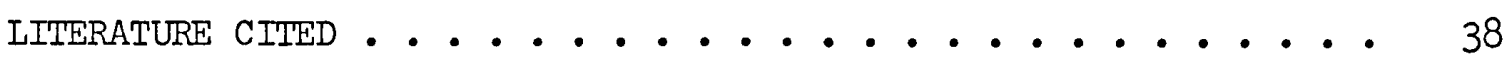

TABIES $1-5$

PLATES 1-11 
NOTATION

ap Aircraft passes

A Area under distribution curve

$A_{M}, A_{N}$ Single tire contact area of main tires and nose tires, respectively (see fig. 8)

B Total number of cycles (one landing and one takeoff); also, main gear wheel spacing (see fig. 8)

$c, c^{\prime} \quad$ Coverages

$\left.\mathrm{C}_{i}, \mathrm{C}_{\mathrm{x}}\right\}$ 'Maximum ordinates of theoretical normal distribution, GND,

$\left.\mathrm{C}_{\mathrm{xc}}, \mathrm{C}_{\mathrm{z}}\right\}$ cumulative, and SND curves, respectively

D Center-to-center spacing of nose gear tires (see fig. 8)

gp Gear passes

GND General normal distribution

$N$ Number of wheels in each main landing gear

$\mathrm{N}_{\mathrm{M}}, \mathrm{N}_{\mathrm{N}} \quad$ Number of tires per main landing gear and nose gear assembly, respectively (see fig. 8)

$p \quad$ Wheel passes per inch

$p^{\prime} \quad$ Total number of passes for each wheel

$\mathrm{p} / \mathrm{c} \quad$ Ratio of aircraft passes to coverages (sometimes expressed as operations per coverage $o / c$ )

$(p / c)_{r} \quad p / c$ ratio for runways

$(\mathrm{p} / \mathrm{c})_{t} \quad \mathrm{p} / \mathrm{c}$ ratio for taxiways

$\mathrm{P}_{t}, \mathrm{P}_{\mathrm{w}} \quad$ Passes of aircraft center line and tire center line, respectively

S Center-to-center wheel spacing

$S_{m}, S_{t}, S_{r} \quad$ Center-to-center wheel spacing for twin wheels, tandem wheels, and outrigger wheels, respectively

SND Standard normal distribution

$\mathrm{T}_{\mathrm{W}} \quad$ Tread 
$u \quad$ Mean value in GND

wp Wheel passes

W Maximum lateral movement of a point on the center line of an aircraft about the center line (or guideline) on runways and taxiways, respectively, during operation of an aircraft

$W_{b} \quad$ Wheel base

$W_{M}, W_{N} \quad$ Width of single-tire contact area for main and nose tires, respectively (see fig. 8)

$\mathrm{W}_{r} \quad$ Wander on runway

$W_{t} \quad$ Width of tire contact area

$\mathrm{W}_{\mathrm{W}} \quad$ Wander width

$\mathrm{W}_{\mathrm{x}} \quad$ Wander on taxiway

$\mathrm{W}_{75}$ Width over which the center line of aircraft traffic is distributed 75 percent of the time

$x \quad$ Variable in GND

$\mathrm{Z}$ Variable in SND

$\alpha_{i} \quad$ Location weighting function

$\sigma, \sigma_{i}, \sigma_{x} \quad$ Standard deviations

$\phi(\mathrm{z})$ standard normal density function 
CONVERSION FACTORS, BRITISH TO METRIC UNITS OF MEASUREMENT

British units of measurement used in this report can be converted to metric units as follows:

\begin{tabular}{llll}
\multicolumn{1}{c}{ Multiply } & \multicolumn{1}{c}{ By } & & \multicolumn{1}{c}{ To Obtain } \\
\cline { 1 - 2 } inches & 2.54 & & centimeters \\
feet & 0.3048 & meters \\
square inches & 6.4516 & square centimeters \\
pounds (force) per square inch & 0.6894757 & newtons per square centimeter
\end{tabular}




\section{SUMMARY}

In the development of pavement design and evaluation criteria for aircraft with complex gear configurations (C-5A, B-747, etc.), it has been revealed that current procedures for relating aircraft operations (passes) to pavement coverages (stress and/or deflection repetitions) are cumbersome and inaccurate.

The procedure for converting aircraft passes to pavement coverages has been reexamined by developing theoretical normal traffic distribution curves and fitting these curves to the limited number of actual traffic distribution curves available for four aircraft (B-47, $\mathrm{B}-52$, $\mathrm{KC}-97$, and $\mathrm{KC}-135)$. In this manner, more realistic pass-tocoverage $(p / c)$ ratios have been developed for most currently used military and civil aircraft.

The revised $\mathrm{p} / \mathrm{c}$ ratios are presented and are recommended for use in pavement design and evaluation criteria. The amount of actual traffic distribution data is recognized to be minimal, and additional data for new generations of aircraft are needed to verify or revise the presented $\mathrm{p} / \mathrm{c}$ ratios. 
PART I: TNTRODUCTION

1. During the early stages of development of criteria for the design and evaluation of pavements, it became apparent that a method of accounting for repetitions of traffic was needed. To simply count the number of aircraft using an airfield facility is not adequate. The incremental detriment to a pavement caused by a particular wheel of a particular aircraft at a particular location is influenced by many factors. Some of these factors are: (a) number of wheels, (b) wheel configuration, (c) load on each wheel, (d) tire contact pressure, (e) location of aircraft on the pavement, and ( $f$ ) previous loading history.

2. In an attempt to normalize these various factors so that one number could be obtained to reflect their collective influence on the total system of design and evaluation, the concept of coverages was introduced. As a result of different assumptions and development procedures used in analyzing results of traffic tests, the term "coverage" has different meanings for rigid and flexible pavements. For rigid pavements, coverage is a measure of the number of maximum stress applications that occur within the pavement due to the applied traffic. A coverage occurs when each point in the pavement within the limits of the traffic lane has been subjected to a maximum stress, assuming that the stress is equal under the full tire print. For flexible pavements, coverage is a measure of the number of maximum stress applications that occur on the surface of the pavement due to the applied traffic. A coverage occurs when all points on the pavement surface within the traffic lane have been subjected to one application of maximum stress, assuming that the stress is equal under the full tire print. Thus, for instance, a twin-tandem gear would produce two applications of stress on the surface of a flexible pavement but would produce only one maximum stress application within a rigid pavement if the tandem spacing were small and two maximum stresses if the tandem spacing were large. For 
this study, the definition of coverage as applied to flexible pavements was used for the development of aircraft pass per coverage ( $p / c)$ ratios. The adjustment for multiple stresses resulting from tandem wheels on rigid pavements was then applied to the developed $\mathrm{p} / \mathrm{c}$ ratios.

3. Test sections have been used to develop the relationship between load, traffic (coverages), and pavement thickness requirements. Traffic on the test sections is programmed so that successive wheel pathis do not overlap and an accurate determination of coverages can be made. It is considered that these test section coverages relate directly to coverages on an airfield facility; however, it is recognized that the $\mathrm{p} / \mathrm{c}$ ratio used on the test section and that occurring on the actual facility are different. Since the random traffic on an airfield can only be conveniently counted as aircraft passes, the development of the $\mathrm{p} / \mathrm{c}$ ratio was essential so that test section relationships could be applied to airfield pavement design or evaluation.

4. The background leading to the development and application of the current method for determining the $p / c$ ratios is presented herein, and it is shown that these $\mathrm{p} / \mathrm{c}$ ratios, especially for aircraft employing complex gears, do not produce distributions that agree well with those developed from actual measurements and observations. Therefore, a new method for determining the $\mathrm{p} / \mathrm{c}$ ratio was developed and used to compute $\mathrm{p} / \mathrm{c}$ ratios for most of the currently used military and civil aircraft. 


\section{Historical Background}

5. In one of the earliest (1942) pavement test sections, stockton No. I, accumulations of traffic were simply reported as wheel load repetitions. $^{1}$ The moving wheels were programmed so that three nonoverlapping but (theoretically) touching wheel paths were obtained. That is, for every three passes of a wheel, every point on the traffic lane was subjected to the print of a wheel one time (fig. 1).

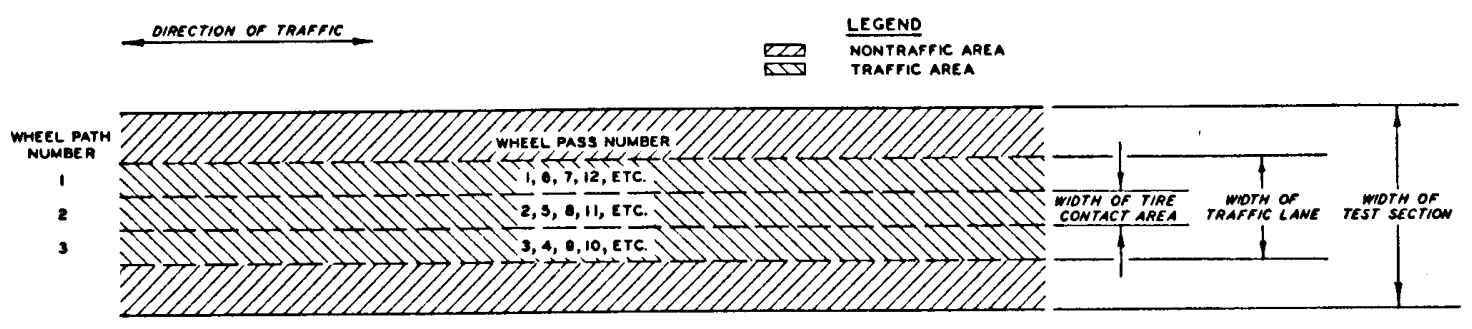

Fig. 1. Typical test section application of nondistributed single-wheel traffic

6. The next significant test section was constructed at Barksdale Field in $1944^{2}$ In this study, the pattern of programmed traffic was described in terms of coverages where a coverage was defined as "one pass of the wheel load over each point in the tracking (traffic) lane." Referring to fig. I, three passes would produce one coverage. In all subsequent test section studies, repetitions of programed traffic have been recorded in terms of coverages.

7. It is well known that aircraft traffic does not follow such a methodical pattern. Furthermore, it has been proposed, with substantiating evidence, that the sharp discontinuity between the traffic areas and nontraffic areas (fig. I) causes unrealistic behavior. Test section traffic is now commonly distributed as shown in fig. 2. In this pattern, wheel paths 3 and 4 receive equal amounts of the applied traffic, and the other paths receive less. The maximum number of coverages (occurring in wheel paths 3 and 4 ) is recorded during testing and at failure. The number of coverages in the other lanes is of no consequence, as these 


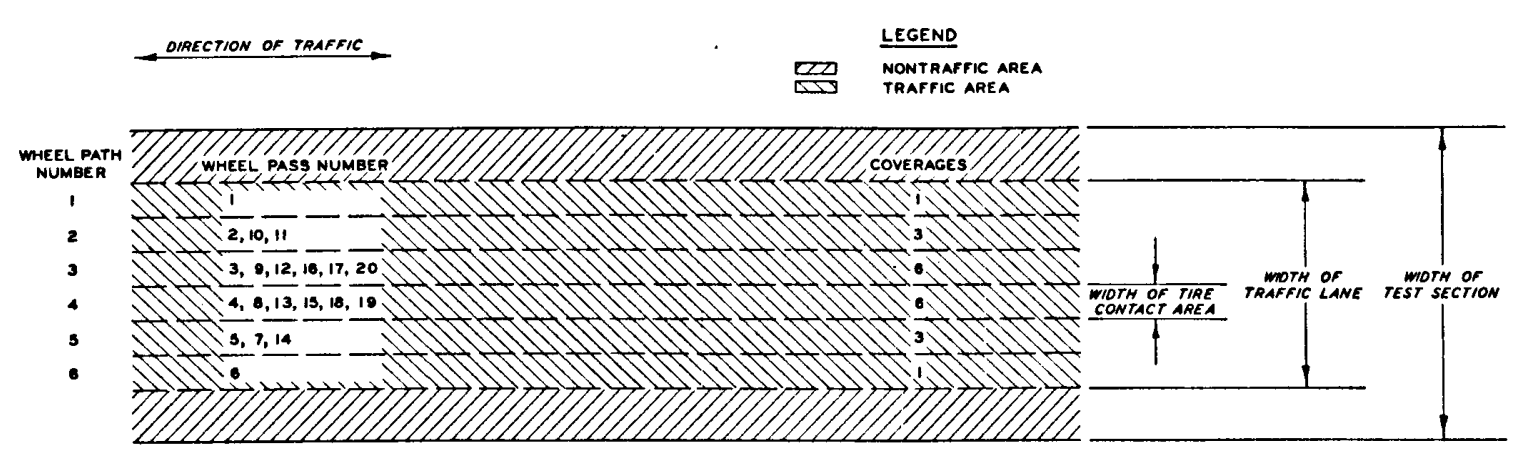

Fig. 2. Typical test section application of distributed single-wheel traffic

repetitions are provided to distribute the traffic and prevent the sharp discontinuity between traffic and nontraffic areas.

8. It is assumed that the coverages to failure are the same for a test section and an airfield facility when both are subjected to the same loadings. In design, therefore, the predicted number of aircraft passes is converted to coverages using the applicable $\mathrm{p} / \mathrm{c}$ ratio, and the test track coverage versus thickness relations can be applied directly to the airfield facility.

9. The $\mathrm{p} / \mathrm{c}$ ratio, sometimes called operations per coverage $(0 / \mathrm{c})$ ratio, was first described in a letter entitled "Design Curves for Less than Capacity Operations," dated 18 April 1949.3 In this letter, it was pointed out that the conversion from cycles based upon the following assumptions was reasonable:

a. Each runway is serviced by two taxiways, and a cycle of operation (one landing and one takeoff) applies one pass to each taxiway and two passes to the runway.

b. Seventy-four percent of all operations on the runway are such that the tire tracks for each gear are uniformly distributed over a $25 \mathrm{ft*}$ width.

c. Seventy-five percent of all operations on the taxiways are such that the tire tracks for each gear are uniformly distributed over a $12.5 \mathrm{ft}$ width.

d. All operations at the field are on the same runway. Using these assumptions, the following relationships were developed:

* A table of factors for converting British units of measurement to metric units is presented on page ix. 


$$
c(\text { taxiways })=\frac{0.75 \mathrm{BNW}_{\mathrm{t}}}{12.5 \times 12} ; c \text { (runways) }=\frac{0.75(2 \mathrm{~B}) \mathrm{NW}_{\mathrm{t}}}{25 \times 12}
$$

where:

$$
\begin{aligned}
c & =\text { coverages } \\
B & =\text { total number of cycles of operation } \\
N & =\text { number of wheels in each main landing gear* } \\
W_{t} & =\text { width of tire print in inches }
\end{aligned}
$$

Based on the assumptions presented above, the number of cycles required to produce one coverage on either a taxiway or a runway is equal to $200 / \mathrm{NW}_{\mathrm{t}}$.

10. The assumed uniform distribution of traffic described above is shown graphically in fig. 3a for runways and fig. $3 \mathrm{~b}$ for taxiways. The equation for $\mathrm{p} / \mathrm{c}$ can be determined mathematically as shown in the following paragraphs.

11. Consider an aircraft with single-wheel tricycle gear (see fig. 4). In fig. 3a, one wheel is assumed to be in the zone $a b=(12 \times 25$ in. $) 75$ percent of the time. If the width of tire print is $w_{t}$ in., then $(12 \times 25) / w_{t}$ wheel passes wp will be required to produce one coverage of the width $a b$. Thus, the average number of wheel passes per inch $\mathrm{P}=\left[(12 \times 25) / \mathrm{w}_{t}\right][1 /(12 \times 25)]=1 / \mathrm{w}_{t}(\mathrm{wp} /$ in.) . That is, the ordinate after one coverage is $1 / w_{t}$ (wp/in.) and the ordinate after $c^{\prime}$ coverages is $c^{\prime} / W_{t}$ (wp/in.) or the coverages after the total number of passes for each wheel $p^{\prime}$ is $\left(c^{\prime} / w_{t}\right) w_{t}=c^{\prime}(w p)$. Now, considering both gears, the total number of wheel passes $=2 p^{\prime}(w p)$, but one aircraft pass equals two wheel passes, and the maximum ordinate has not changed. Thus, by definition

* In normal operation, the load on the nose gear wheels is considerably less than that on the main gear wheels, and traffic generated by the nose gear wheels is of minimum consequence; therefore, the nose gear wheels have been consistently ignored in traffic distribution studies. The $\mathrm{p} / \mathrm{c}$ ratios discussed and presented in this report are not relevant to nose gear wheel traffic. 


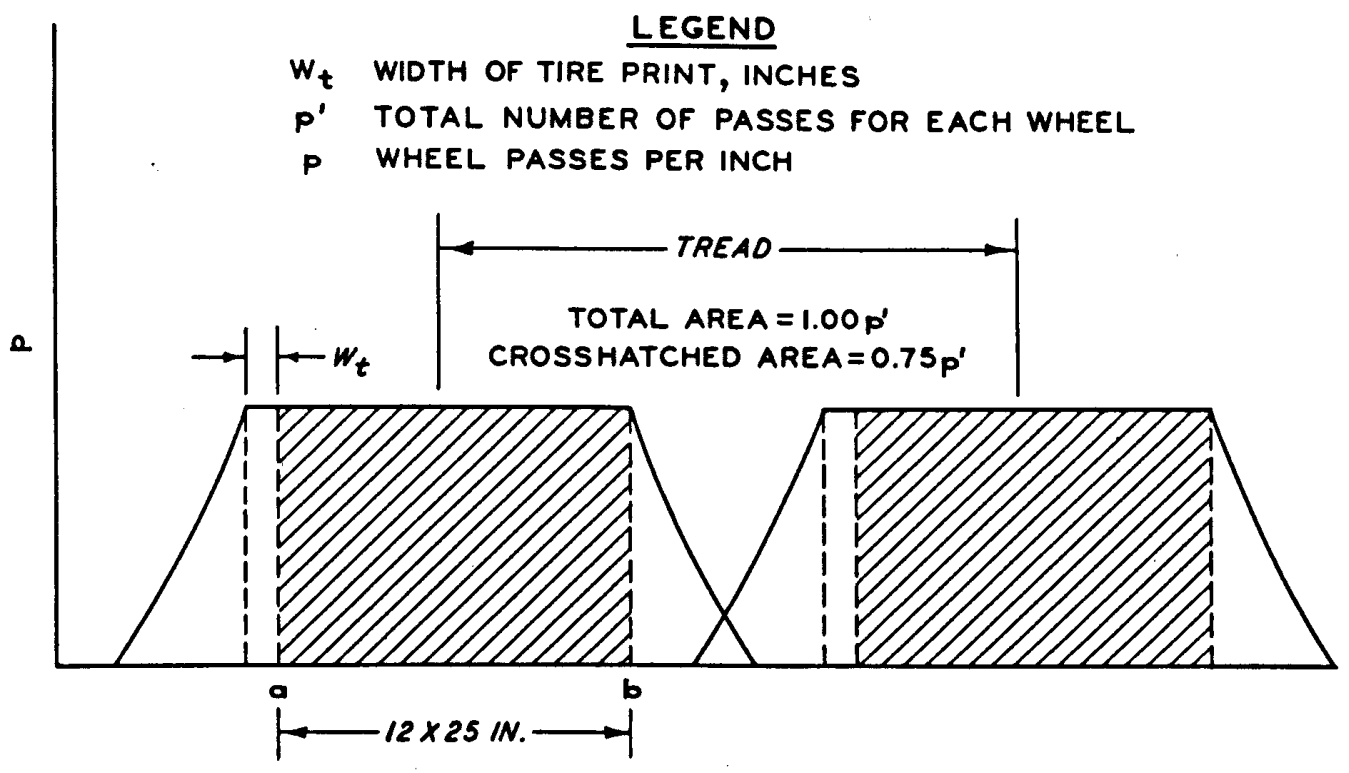

LATERAL PLACEMENT OF CENTER LINE OF WHEEL, IN.

\section{a. RUNWAY}

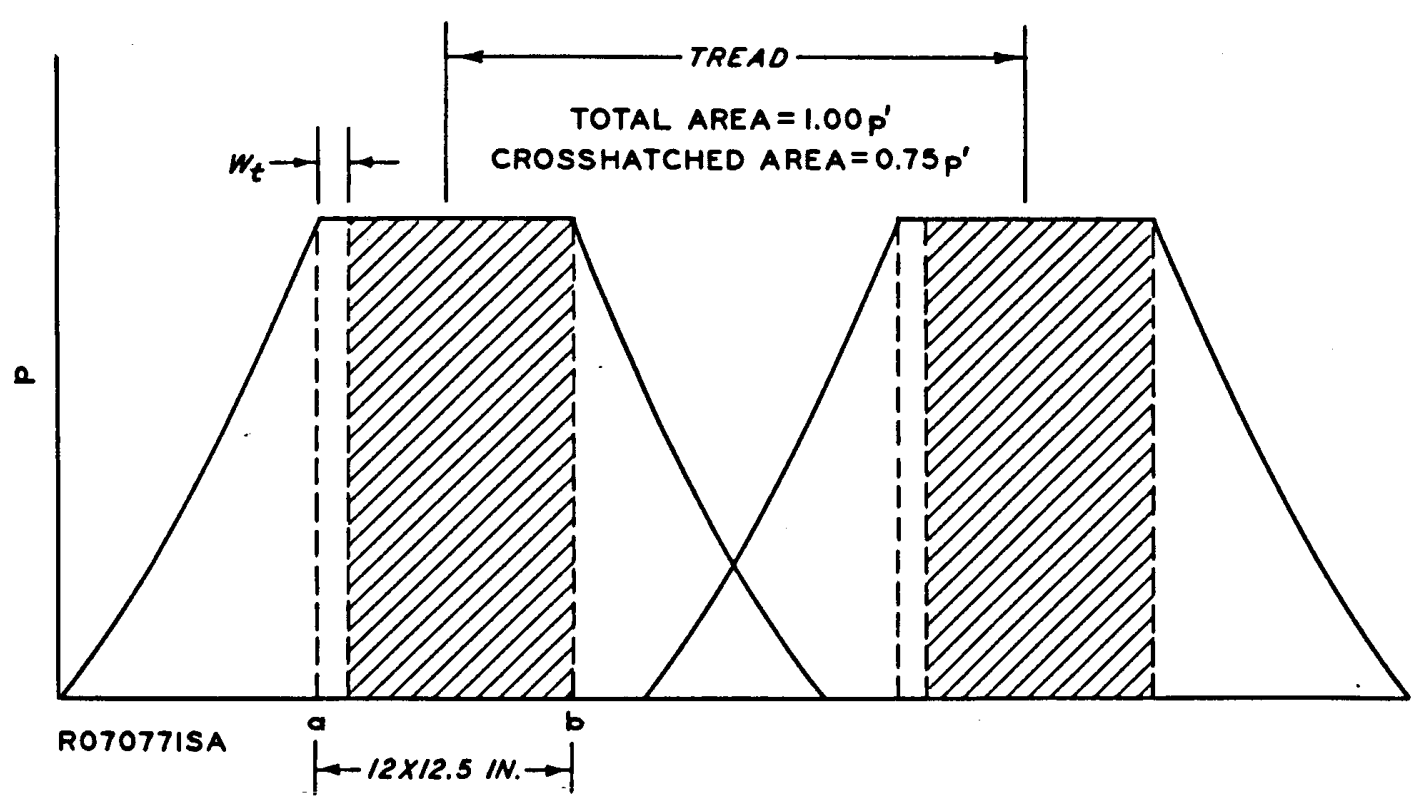

LATERAL PLACEMENT OF CENTER LINE OF WHEEL, IN.

b. TAXIWAY

Fig. 3. Theoretical uniform distribution of aircraft traffic on runways and taxiways 


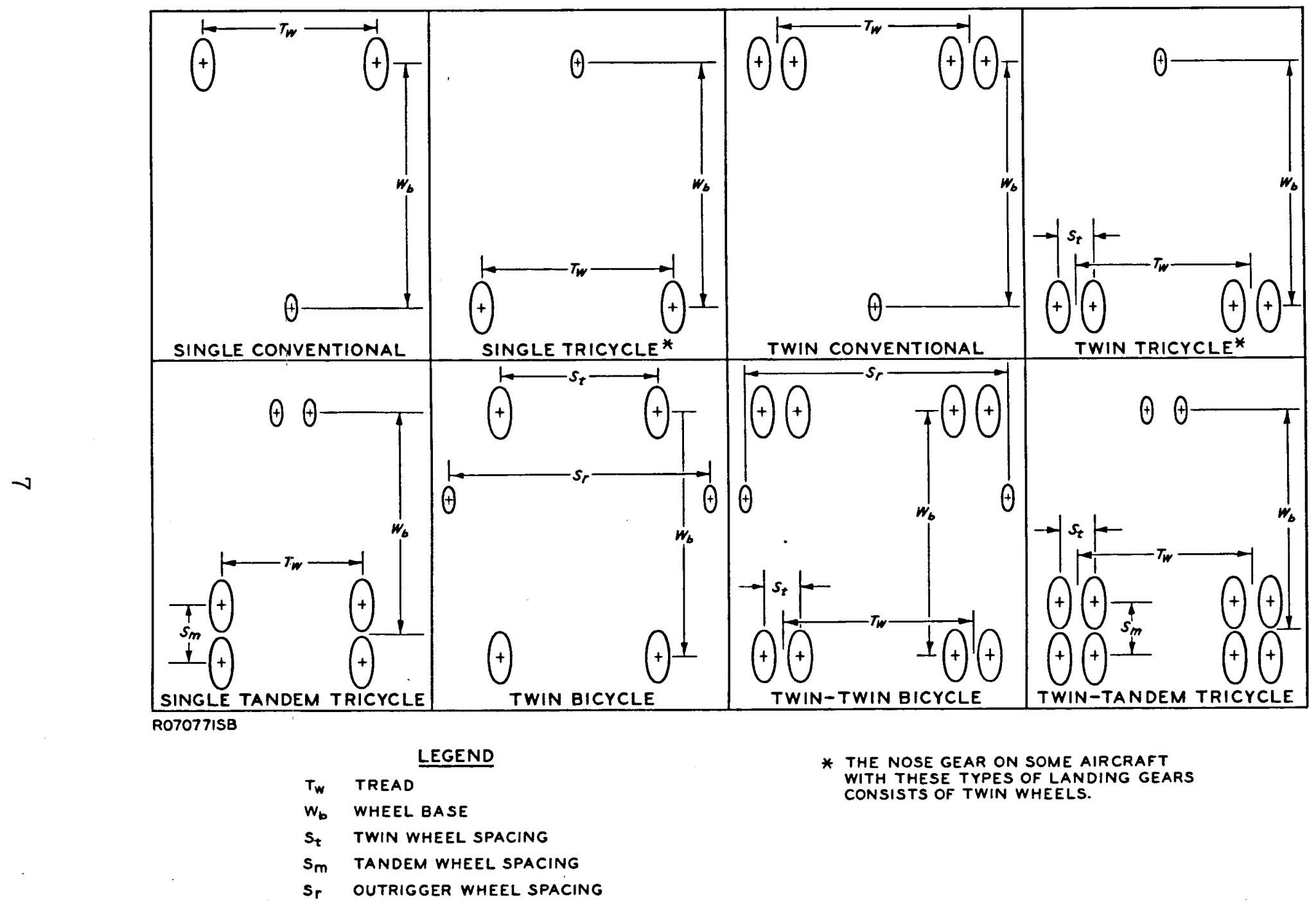

Fig. 4. Wheel configurations for typical aircraft landing gears 


$$
\begin{aligned}
\frac{p}{c} & =\frac{\text { total number of aircraft passes }}{\text { coverages }}\left(\frac{a p}{w p}\right) \\
& =2 p^{\prime}(w p) \frac{1}{2}\left(\frac{a p}{w p}\right)\left(\frac{w_{t}}{c^{\prime}}\right) \frac{1}{W_{t}}\left(\frac{1}{w p}\right) \\
& =\frac{p^{\prime}}{c^{\prime}}\left(\frac{a p}{w p}\right)
\end{aligned}
$$

However, from fig. 3a:

$$
\begin{aligned}
0.75 p^{\prime} & =\left(\frac{c^{\prime}}{w_{t}}\right)(12 \times 25) \\
p^{\prime} & =\frac{c^{\prime}(12 \times 25)}{(0.75)\left(w_{t}\right)}
\end{aligned}
$$

Thus

$$
\begin{aligned}
\frac{p}{c} & =\frac{c^{\prime}(12 \times 25)}{c^{\prime}(0.75)\left(w_{t}\right)} \\
& =\frac{12 \times 25}{0.75\left(w_{t}\right)}\left(\frac{a p}{w p}\right)
\end{aligned}
$$

12. Consider now a bicycle gear with $N$ wheels per gear and neglect the outrigger wheels. The maximum ordinate is now $\left(c^{\prime} / N_{t}\right)(w p / i n$.$) .$ For one main gear, the total number of wheel passes equals $p^{\prime}$ and the number of gear passes (gp) equals $\left(\mathrm{p}^{\prime} / \mathrm{N}\right)$. For both main gears, the total number of gear passes equals $\left(2 \mathrm{p}^{\prime} / \mathrm{N}\right)(\mathrm{gp})$ but one aircraft pass equals two gear passes and the maximum ordinate has not changed. Thus, as before

$$
\begin{aligned}
\frac{p}{c} & =\frac{\text { total number of aircraft passes }}{\text { coverages }}\left(\frac{a p}{w p}\right) \\
& =\left(\frac{2 p^{\prime}}{N}\right)(g p) \frac{1}{2}\left(\frac{a p}{w p}\right)\left(\frac{N W_{t}}{c^{\prime}}\right)\left(\frac{1}{W_{t}}\right)\left(\frac{1}{w p}\right) \\
& =\frac{p^{\prime}}{c^{\prime}}\left(\frac{a p}{w p}\right)
\end{aligned}
$$

However, from fig. 3a:

$$
\begin{aligned}
0.75 p^{\prime} & =\left(\frac{c^{\prime}}{N W_{t}}\right)(12 \times 25) \\
p^{\prime} & =\frac{c^{\prime}(12 \times 25)}{0.75(N)\left(W_{t}\right)}
\end{aligned}
$$


Thus

$$
\begin{aligned}
\frac{p}{c} & =\frac{c^{\prime}(12 \times 25)}{c^{\prime}(0.75)(\mathrm{N})\left(\mathrm{w}_{t}\right)} \\
& =\frac{12 \times 25}{0.75(\mathrm{~N})\left(\mathrm{W}_{t}\right)}\left(\frac{\mathrm{ap}}{\mathrm{wp}}\right)
\end{aligned}
$$

This equation is the same as that given previously for runways. Similarly, the equation for taxiways can be developed. Thus, the equations for $\mathrm{p} / \mathrm{c}$ ratios are written as follows:

$$
\begin{aligned}
& \left(\frac{p}{c}\right)_{t}=\frac{12.5 \times 12}{0.75(\mathrm{~N})\left(\mathrm{W}_{t}\right)} \quad \text { (for taxiways) } \\
& \left(\frac{p}{c}\right)_{r}=\frac{25 \times 12}{0.75(\mathrm{~N})\left(\mathrm{w}_{t}\right)} \quad \text { (for runways) }
\end{aligned}
$$

where $\mathrm{p} / \mathrm{c}$ denotes aircraft'passes/coverage ratio, $c$ has units of wheel passes, $\mathbb{N}$ denotes number of wheels of each main gear, and $W_{t}$ denotes tire width, in.

13. In order to obtain actual traffic distribution data, a count of traffic at four B-47 bases was conducted and reported in $19566^{4}$ of particular interest was the influence of traffic distribution following center-line stripes (traffic guidelines), which had become common and had led to a considerable degree of channelization of traffic. It was reported that 75 percent of the main gear traffic on the straightways of taxiways fell in a lane 7.5 ft wide (see fig. 5). For most takeoffs, the main gear traffic occurred in an area with a width of about $30 \mathrm{ft}$ at runway ends. The data for the reference 4 study were collected for $\mathrm{B}-47$ and $\mathrm{KC}-97$ aircraft.

14. As a result of this study, a letter dated 6 January 1956* was written recommending a revision of coverage criteria for capacity operation. It was suggested that the $\mathrm{p} / \mathrm{c}$ value for nonchannelized traffic should be five times the value for channelized traffic. This multiplier was selected because:

* U. S. Army Engineer Waterways Experiment Station, CE, "Revised Coverage Criteria," Letter to the Chief of Engineers (ENGER), 6 Jan 1956. 

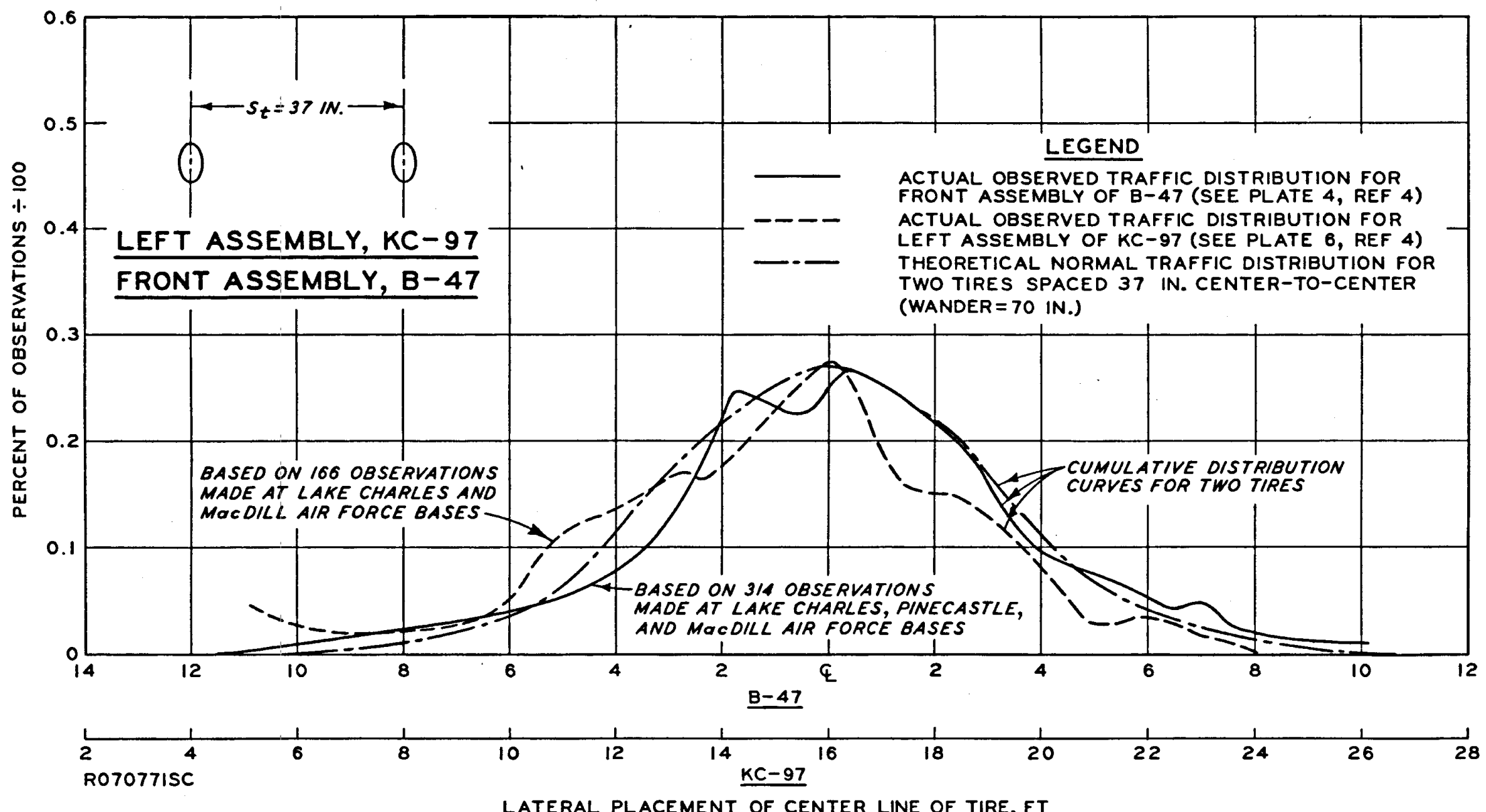

Fig. 5. Distribution of B-47 aircraft traffic along straightways of taxiway 
The channelized traffic report shows 75 percent of B-47 traffic on channelized areas to fall within a strip 7.5 ft wide,.... In similar developments for runways (nonchannelized areas) earlier criteria were extended. The early criteria showed 75 percent of traffic in a 50-ft band, which for the 20- to 25-ftwheel-span aircraft of that time meant a 25- to 30ft wander width. This was for 150-ft runway widths. With wider runways and newer aircraft sizes, types, and gear configurations, it is considered reasonable to increase this by 30 to 50 percent. This gives a 75 percent tracked width of about $38 \mathrm{ft}$.

In accordance with this analysis of field data, equations 1 and 2 were revised as follows:

$$
\begin{array}{ll}
\left(\frac{p}{c}\right)_{t}=\frac{7.5 \times 12}{0.75(N)\left(W_{t}\right)} & \text { (for taxiways) } \\
\left(\frac{p}{c}\right)_{r}=\frac{38 \times 12}{0.75(N)\left(W_{t}\right)} & \text { (for runways) }
\end{array}
$$

Thus, the $\mathrm{p} / \mathrm{c}$ ratio for the $\mathrm{B}-47$ was calculated as follows:

$$
\begin{aligned}
\mathrm{W}_{t} & =14.3 \mathrm{in} . \\
N & =4 \\
\left(\frac{p}{c}\right)_{t} & =\frac{(7.5)(12)}{(0.75)(4)(14.3)}=2.10 \text { for taxiways } \\
\left(\frac{p}{c}\right)_{r} & =\frac{(38)(12)}{(0.75)(4)(14.3)}=10.63 \text { for runways }
\end{aligned}
$$

15. A second survey 5 was conducted at seven Air Force bases to record the lateral distribution of $\mathrm{B}-47, \mathrm{~B}-52, \mathrm{KC}-97$, and $\mathrm{KC}-135$ aircraft (see plates 1-8). The conclusions of this study are quoted in part as follows:

It is concluded that: (a) channelized traffic occurs on runways during takeoffs and to a lesser extent during landings; (b) the width in which channelization of B-47 traffic occurs on runways is about three times greater than the width $(7.5 \mathrm{ft})$ in which 
it occurs on taxiways; (c) the B-52 tends to use about the same width of runway as of taxiway;

(d) due to their gear layout, the $\mathrm{KC}-135$ and $\mathrm{KC}-97$ travel in a slightly wider path than do the $\mathrm{B}-47$ or B-52; and (e) the variation in climatic conditions at the fields investigated did not appear to have any effect on the operational characteristics of the aircraft in relation to takeoffs and landings.

16. As a result of the two investigations 4,5 discussed in paragraphs 13, 14, and 15, the concept of wander was introduced. Under this concept, the width of the traffic lane, in which 75 percent of the traffic falls, is not specified as a constant dimension (7.5 ft for taxiways and $38 \mathrm{ft}$ for runways) but is divided into its components: width of tire contact area $W_{t}$, center-to-center wheel spacing $S$, and wander $W$, where wander is defined as the maximum lateral movement of a point on the center line of an aircraft about the center line (or guideline) on taxiways or runways during operation of the aircraft. Thus, equations 3 and 4 were rewritten as follows:

$$
\begin{aligned}
& \left(\frac{p}{c}\right)_{t}=\frac{W_{t}+s+W}{0.75(N)\left(W_{t}\right)} \quad \text { (for taxiways) } \\
& \left(\frac{p}{c}\right)_{r}=\frac{W_{t}+s+W}{0.75(N)\left(W_{t}\right)} \quad \text { (for runways) }
\end{aligned}
$$

The B-47 aircraft was used to develop new equations for determining $\mathrm{p} / \mathrm{c}$ ratios. Specific values for the B-47 landing gear (fig. 6) were used to divide the traffic lane width (numerator of equations 5 and 6 ) into its components as shown in fig. 7. For the B-47 with a tire width $W_{t}$ of $14.3 \mathrm{in}$. and a center-to-center wheel spacing $\mathrm{S}$ of $37 \mathrm{in.}$, the wander for taxiways $W$ is $38.7 \mathrm{in}$; for runways, $W$ is $404.7 \mathrm{in}$. These values for wander for the B-47 were rounded off to 40 and 410 , respectively, and were used in revisions of equations 5 and 6 as follows:

$$
\left(\frac{p}{c}\right)_{t}=\frac{w_{t}+s+40}{0.75(N)\left(w_{t}\right)} \quad \text { (for taxiways) }
$$



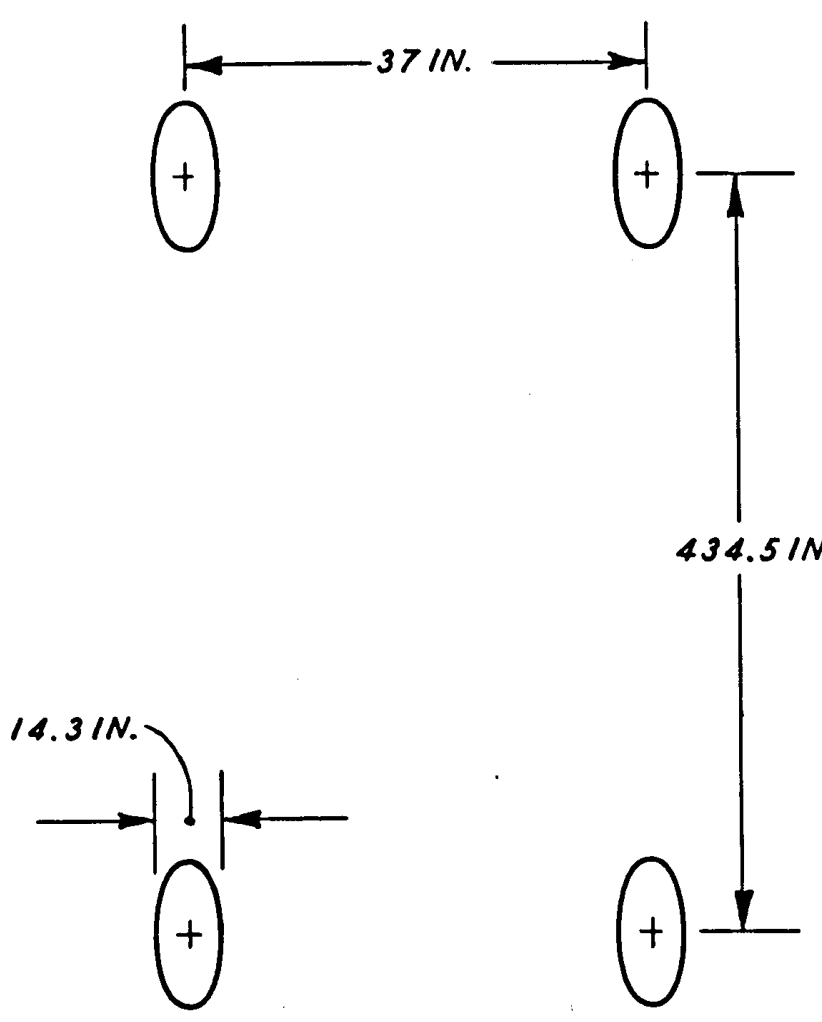

Fig. 6. Twin bicycle gear configuration for $\mathrm{B}-47$ aircraft

$$
\left(\frac{p}{c}\right)_{r}=\frac{w_{t}+s+410}{0.75(N)\left(W_{t}\right)} \quad \text { (for runways) }
$$

Comparison of $\mathrm{p} / \mathrm{c}$ ratios determined through use of equations 7 and 8 with similar ratios based on actual traffic indicated that $\mathrm{p} / \mathrm{c}$ ratios determined through use of equations 7 and 8 do not agree very well with those determined using actual traffic distribution. Since very little actual traffic distribution data were available for further development, equation 7 was adopted for further use in determining $\mathrm{p} / \mathrm{c}$ ratios. This equation is currently used to determine $p / c$ ratios for all aircraft for both taxiways and runways.

17. In publications prepared by the Air Force Systems Command at Wright-Patterson AFB, Ohio, the U. S. Air Force has proposed several variations of equation 7 for use in determining $p / c$ ratios. The Air Force has concluded that (a) a large percentage of aircraft landings are made at reduced loads and that traffic resulting from landings is of 


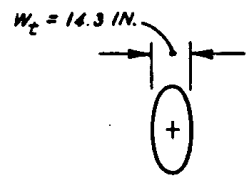

$\Theta$

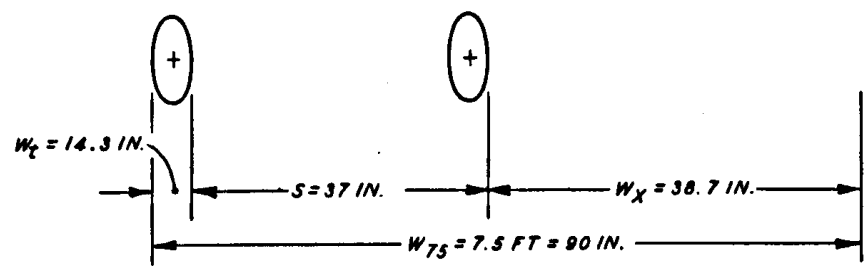

o. TAXIWAY (CHANNELIZED TRAFFIC)
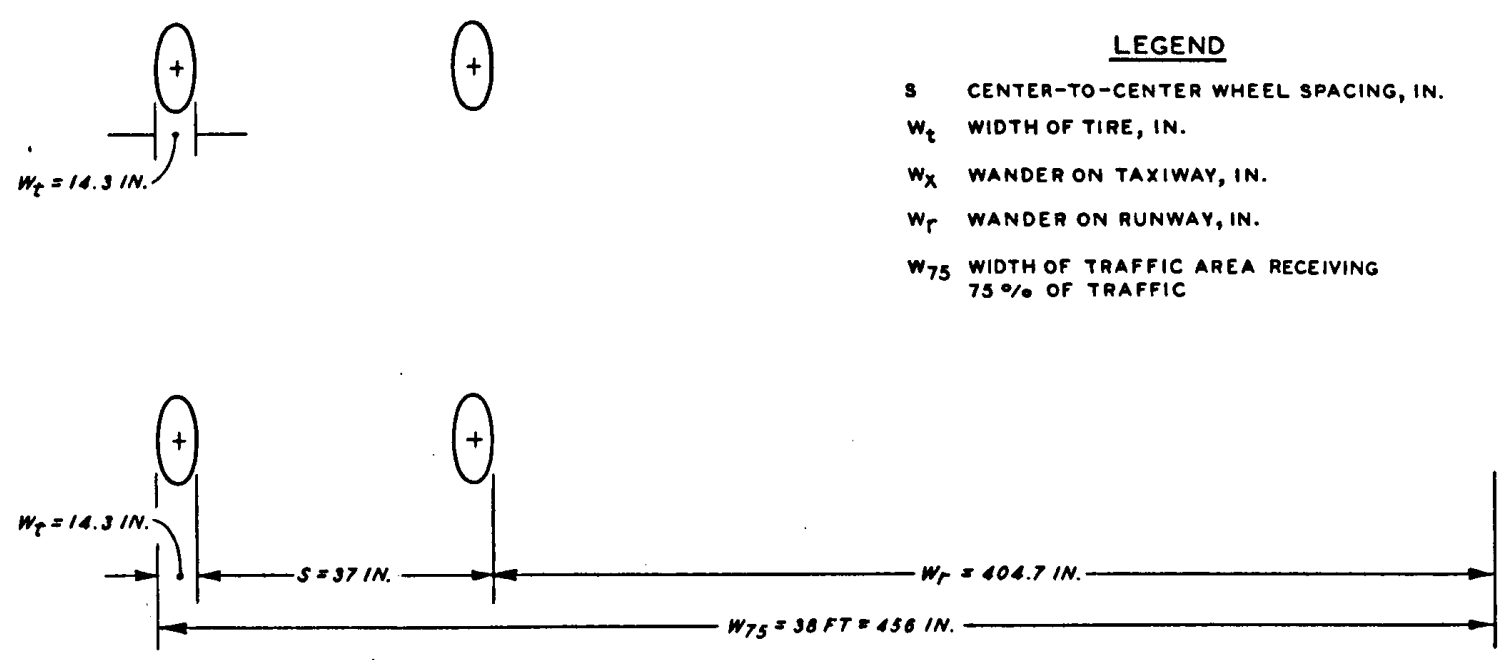

\section{b. RUNWAY (NONCHANNELIZED TRAFFIC)}

Fig. 7. Traffic lane receiving 75 percent of $B-47$ aircraft traffic

small consequence, and (b) that wander of a fully loaded aircraft for takeoff is about the same as wander along the taxiway. One Air Force publication ${ }^{6}$ suggests the use of the following equations for determining $\mathrm{p} / \mathrm{c}$ ratios:

$$
\left(\frac{p}{c}\right)=\frac{B+80+W_{M}}{0.75\left(N_{M}\right)\left(W_{M}\right)} \quad \text { (for main gear) }
$$




$$
\left(\frac{p}{c}\right)=\frac{D+80+W_{N}}{0.75\left(N_{N}\right)\left(W_{N}\right)} \quad \text { (for nose gear) }
$$

The terms in these equations are identified in fig. 8. The $\mathrm{p} / \mathrm{c}$ ratio for a particular aircraft (for taxiway or runway) is the smallest ratio resulting from either of these equations.
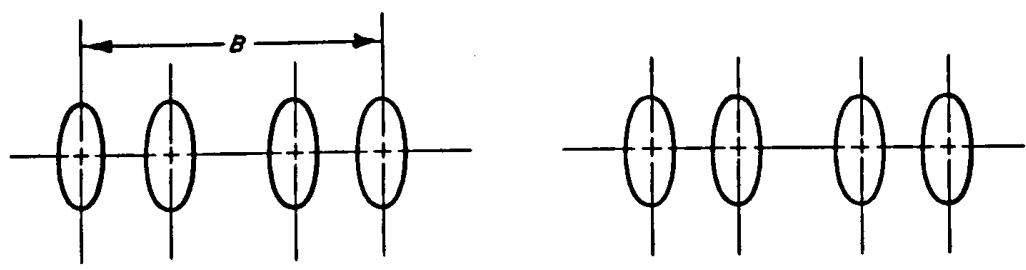

\section{MAIN GEAR}

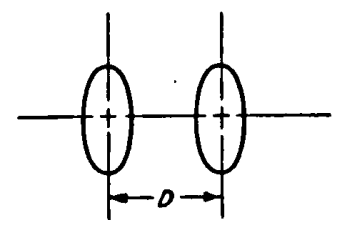

\section{NOSE GEAR}

MAIN ASSEMBLY: $P / C=\frac{8+80+w_{M}}{(0.75)\left(N_{M}\right)\left(w_{M}\right)}$

NOSE ASSEMBLY: $P / C=\frac{0+80+w_{N}}{(0.75)\left(N_{N}\right)\left(W_{N}\right)}$
P/C PASSES PER COVERAGE

$N_{M}$ NUMGER OF TIRES PER MAIN GEAR

$N_{N}$ NUMBER OF TIRES PER NOSE GEAR ASSEMBLY

$W_{M}$ WIDTH OF MAIN SINGLE TIRE CONTACT AREA $W_{M}=0.878 \sqrt{A_{M}}$

$W_{N}$ WIDTH OF NOSE SINGLE TIRE CONTACT AREA $W_{N}=0.878 \sqrt{A_{N}}$

AM SINGLE TIRE CONTACT AREA OF MAIN TIRES

AN SINGLE TIRE CONTACT AREA OF NOSE TIRES

Fig. 8. Suggested Air Force method for determining pass-per-coverage ratio (from reference 6) 
18. In the past, design and evaluation criteria for pavements were prepared for capacity operation. Capacity operation is defined in the Barksdale report ${ }^{2}$ as:
...the maximum traffic that can possibly operate on an airfield for a period of about 20 years. The daily operations may be assumed as varying from 100 cycles of landings and takeoffs for the very heavy airplanes to 1500 cycles for very lightweight planes.

Subsequently, it became necessary to develop criteria for less than capacity operations such as short-term military operations. Furthermore, at the time that center-line striping became common, the effects of channelization had to be considered. These factors were discussed in the letter, "Revised Coverage Criteria," and the following was presented.

Headquarters, U. S. Air Force has suggested using about 6600 operations per year for B-47 aircraft fields. This suggests the following:

\begin{tabular}{|c|c|c|c|}
\hline \multirow[b]{2}{*}{ Time Period } & \multirow[b]{2}{*}{ Operations } & \multicolumn{2}{|c|}{ Coverages } \\
\hline & & Channelized & Nonchannelized \\
\hline 2 weeks & 254 & 119 & 24 \\
\hline 6 months & 3,300 & 1,540 & 304 \\
\hline 2 years & 13,200 & 6,160 & 1,220 \\
\hline 10 years & 66,000 & 30,800 & 6,080 \\
\hline
\end{tabular}

Using these data and attempting to establish reasonable ranges for coverages, operations and evaluation of loads and at the same time incorporating as much existing data as possible, the following has been derived.

\begin{tabular}{|c|c|c|c|c|c|}
\hline \multirow[b]{2}{*}{$\begin{array}{l}\text { Operational } \\
\text { Category }\end{array}$} & \multirow[b]{2}{*}{$\begin{array}{c}\text { Time } \\
\text { Period } \\
\end{array}$} & \multicolumn{2}{|c|}{ Coverages } & \multicolumn{2}{|c|}{ Operations } \\
\hline & & Channelized & $\begin{array}{c}\text { Non- } \\
\text { channelized } \\
\end{array}$ & Channelized & $\begin{array}{c}\text { Non- } \\
\text { channelized }\end{array}$ \\
\hline Capacity & $5-10 \mathrm{yrs}$ & $25,000 *$ & $5000 *$ & $50,000 *$ & $50,000 *$ \\
\hline Full & $1-2$ yrs & 5,000 & 1000 & 10,000 & 10,000 \\
\hline Minimum & 4-6 mos & 1,000 & 200 & 2,000 & 2,000 \\
\hline Emergency & $2-3$ wks & 200 & 40 & 400 & 400 \\
\hline
\end{tabular}

* These to be indicated only as "unlimited." 
19. The tabulation on the preceding page has been used to define operational categories up to the present. However, these values are no longer realistic because many airfields, both military and civilian, are carrying a considerably greater quantity of traffic. Thus, in the future, design and evaluation curves should be presented in terms of aircraft passes (operations). In this case, the $\mathrm{p} / \mathrm{c}$ ratios will normally be required only to convert test section traffic in terms of coverages into equivalent aircraft traffic in terms of aircraft passes. 
20. The discussion in Part II has shown the current stage of development of traffic distribution concepts. Statistical methods have been used to make a more fundamental study, which resulted in the development of improved traffic distribution concepts described in the following paragraphs.

21. A fundamental assumption was made that airfield traffic is normally distributed rather than uniformly distributed as formerly assumed (fig. 3). For a large number of aircraft passes, the statistical representation of the lateral placement of the center line of the aircraft may be as shown in fig. 9. The general shape is assumed to be normal, but the specific shape depends on the standard deviation $\sigma$. The specific shape can also be described by prescribing the wander width $\mathrm{W}$, which is defined as that width over which the center line of aircraft traffic is distributed 75 percent of the time. As will be shown later, wander widths of 70 and 140 in., respectively, will be used for taxiways and muways. These values represent the best values obtainable from existing data and are subject to change.

22. The concept of coverage has been revised for this work. It

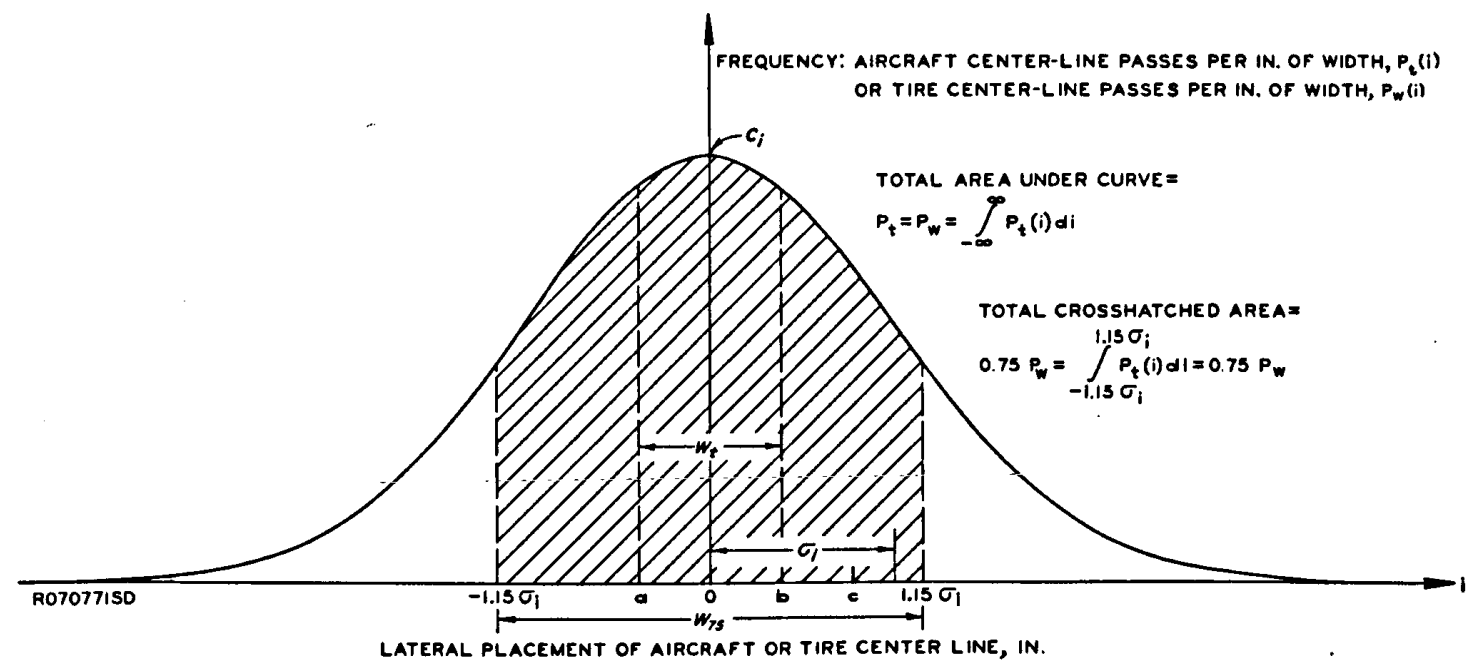

Fig. 9. Theoretical normal distribution of aircraft traffic 
was assumed that coverage represents the maximum number of tire prints or partial tire prints applied to the pavement surface at that point where maximum accumulation occurs. Referring to fig. 9, the curve also represents the distribution of the center line of one wheel on the aircraft. Then, when the wheel center line is at $a=-\left(w_{t} / 2\right)$, wheel passes accumulate at 0 . Similarly, when the wheel center line is between $a=-\left(w_{t} / 2\right)$ and $b=+\left(W_{t} / 2\right)$ accumulations will occur at 0 . By inspection, the maximum number of accumulations will occur at 0 and is equal to:

$$
c=\int_{-\frac{W_{t}}{2}}^{\frac{W_{t}}{2}} P_{t}(i) d i
$$

This is approximately $\left(c_{i}\right)\left(w_{t}\right)$.

23. There is an inherent assumption that the effect of the edge of a tire at $O$ is as detrimental as the effect of the center of the tire at 0 . This is not necessarily so, and a further refinement would be to use a location weighting function $\alpha_{i}$, which would change as the tire center line is moved from the point under consideration (in this case, point 0$)$. The location weighting function would be 1.0 when the center of the tire was directly over the point of maximum accumulations and less than 1.0 as the tire location was moved. Furthermore, it may well be that a tire at location $c$ for example, although not accumulating tire prints at 0 , could be contributing detriment at point $0 . *$ Then, the coverages could be defined as:

$$
c=\int_{-\infty}^{\infty}\left[P_{t}(i) \alpha(i)\right] d i
$$

At this time, this refinement will not be considered and the simplified definition $c=\left(c_{i}\right)\left(w_{t}\right)$ will be used.

24. The method can now be extended to an aircraft having many

* Note also that this is even more true at increasing depths, such as at the surface of the subgrade, etc. 
wheels. The wheel path patterns, such as in fig. 9, are added graphically, and the coverages for the particular aircraft can be determined. The area (A) under all the distribution curves represents the total number of wheel passes. From this use, the $p / c$ ratio can be determined as described in the following paragraphs.

25. The standard normal distribution (SND) curve is shown in fig. 10. Properties of this curve are tabulated in various publications

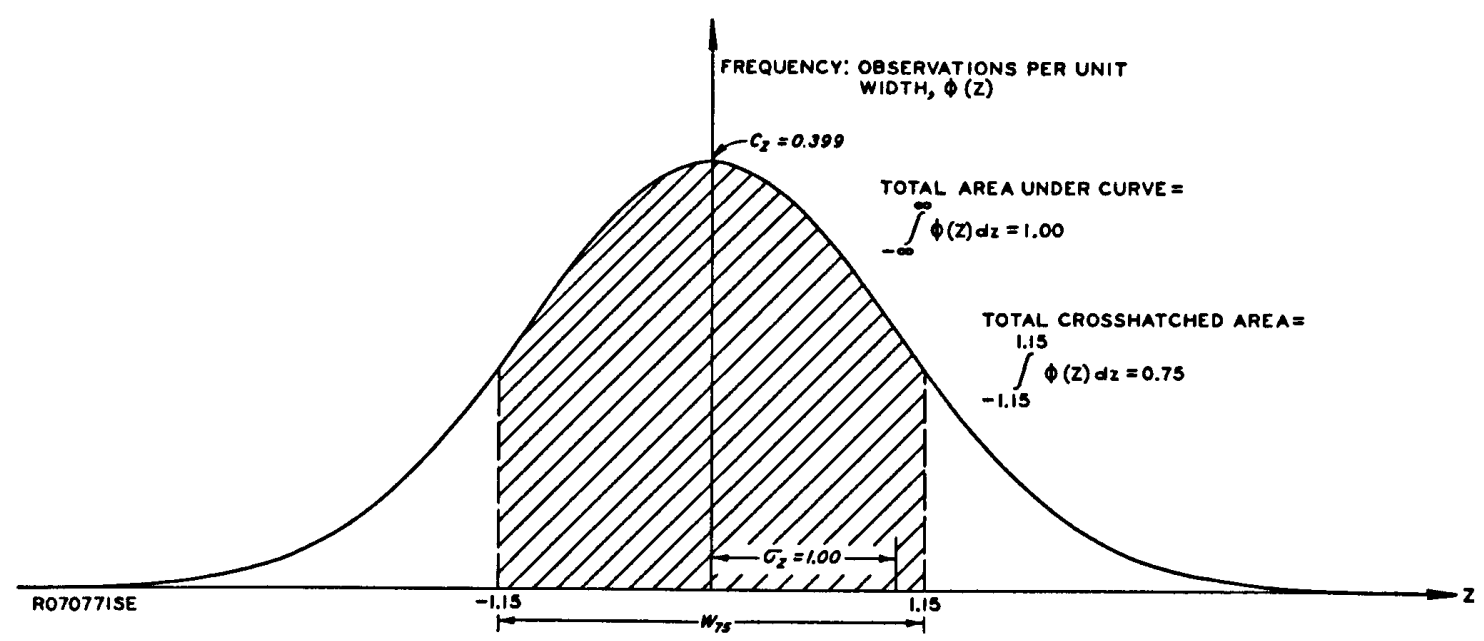

Fig. 10. Standard normal distribution (SND) curve

(for instance, reference 7) and these tabulated values can be used to determine the properties of general normal distributions GND. In the SND,

$$
\begin{aligned}
& \text { Standard deviation, } \sigma=1.0 \\
& \text { Area under the curve, } A=1.0 \\
& \text { Maximum ordinate, } C_{z}=0.399
\end{aligned}
$$

and 75 percent of the area under the curve lies between $-1.15<z<+1.15$. The GND of aircraft traffic can be related to the SND curve using the substitution

$$
z=\frac{x-u}{\sigma_{x}}
$$

where

$$
\mathrm{Z}=\mathrm{a} \text { variable in } \mathrm{SND}
$$


$\mathrm{x}=\mathrm{a}$ variable in GND

$\sigma_{\mathrm{X}}=$ standard deviation in GND

$\mathrm{u}=$ mean value in GND

The GND is shown in fig. 11 for a wander width $W_{W}$ of $70 \mathrm{in.} \mathrm{Therefore,}$

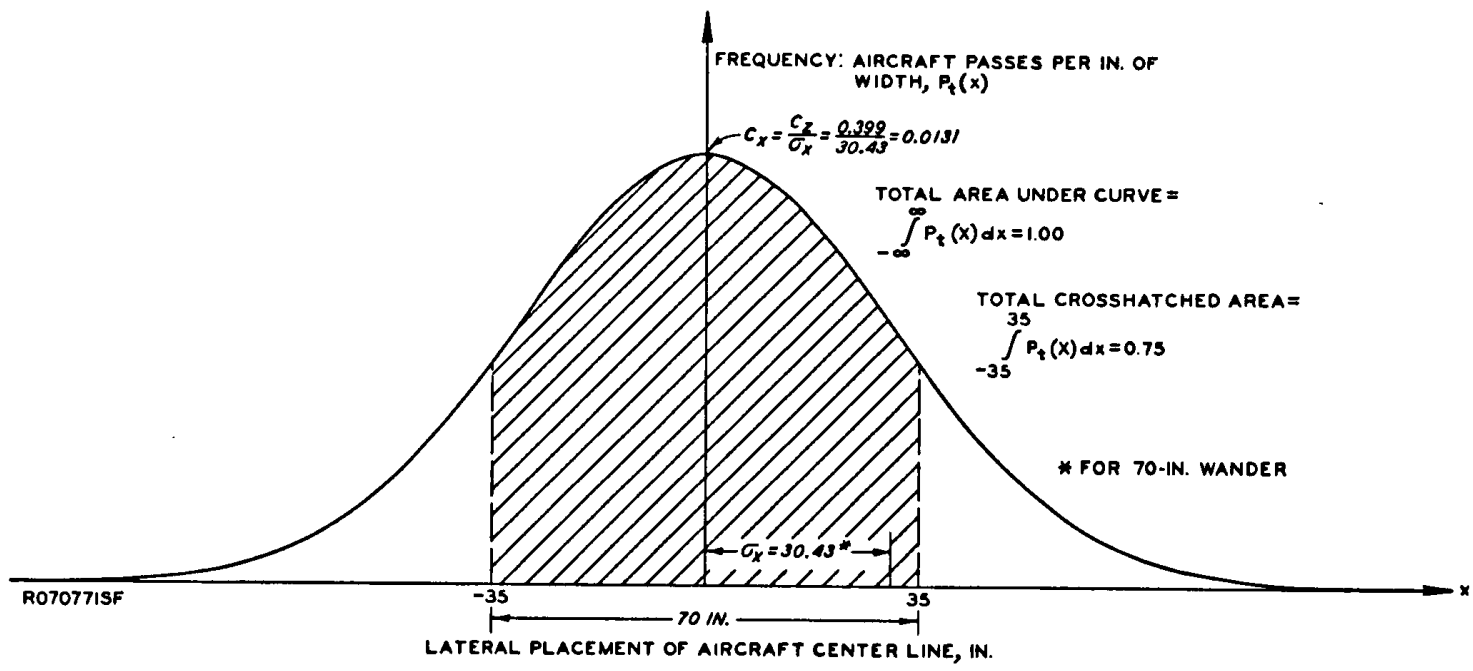

Fig. 11. General distribution (GND) curve for aircraft traffic

75 percent of the wheel paths will be distributed between +35 and -35 in. Hence, using the above substitution with $u=0$,

$$
\begin{aligned}
1.15 & =\frac{35-0}{\sigma_{x}} \\
\sigma_{x} & =30.43
\end{aligned}
$$

Note that as the wander is changed, $\sigma_{x}$ changes also and must be recalculated as shown above. Now the SND curve has the equation

$$
\phi(z)=\frac{1}{\sqrt{2 \pi}} e^{-z^{2} / 2}
$$

where $\phi(z)=$ standard normal density function. The GND curve has the equation

$$
P_{t}(x)=\frac{1}{\sigma_{x} \sqrt{2 \pi}} e^{-1 / 2\left(x-u / \sigma_{x}\right)^{2}}
$$


which, using the substitution $z=(x-u) / \sigma$, becomes

$$
P_{t}(x)=\frac{1}{\sigma_{x}}[\phi(z)]
$$

and

$$
C_{x}=\frac{C_{z}}{\sigma_{x}}=\frac{0.399}{30.43}=0.0131
$$

where $\mathrm{C}_{\mathrm{X}}=$ the maximum ordinate of $\mathrm{GND}$. Also,

$$
\begin{aligned}
\text { the area under the GND curve } & =\int_{-\infty}^{\infty} P_{t}(x) d x \\
& =\int_{-\infty}^{\infty} \frac{1}{\sigma_{x}}[\phi(z)] \sigma_{x} d z \\
& =\int_{-\infty}^{\infty} \phi(z) d z \\
& =1.00
\end{aligned}
$$

26. The theoretical normal distribution can now be applied to real aircraft. Consider, for example, an aircraft with single-wheel tricycle gear (fig. 12). Plotting the theoretical distribution of each wheel and superimposing the patterns, the distribution of fig. 12 is obtained. Graphical addition of these curves does not result in an increase in the value of the maximum ordinate $\mathrm{C}_{\mathrm{x}}$. Therefore, the total area under the curves equals two wheel passes or one aircraft pass, and the maximum coverages equal $\left(\mathrm{C}_{x}\right)\left(\mathrm{w}_{t}\right)$. Thus

$$
\frac{p}{c}=\frac{1}{\left(c_{x}\right)\left(w_{t}\right)}\left(\frac{a p}{w p}\right)
$$

27. As the wheel spacing $S$ becomes smaller, a pattern such as that shown in fig. 13 is obtained. In this case, a graphical addition 


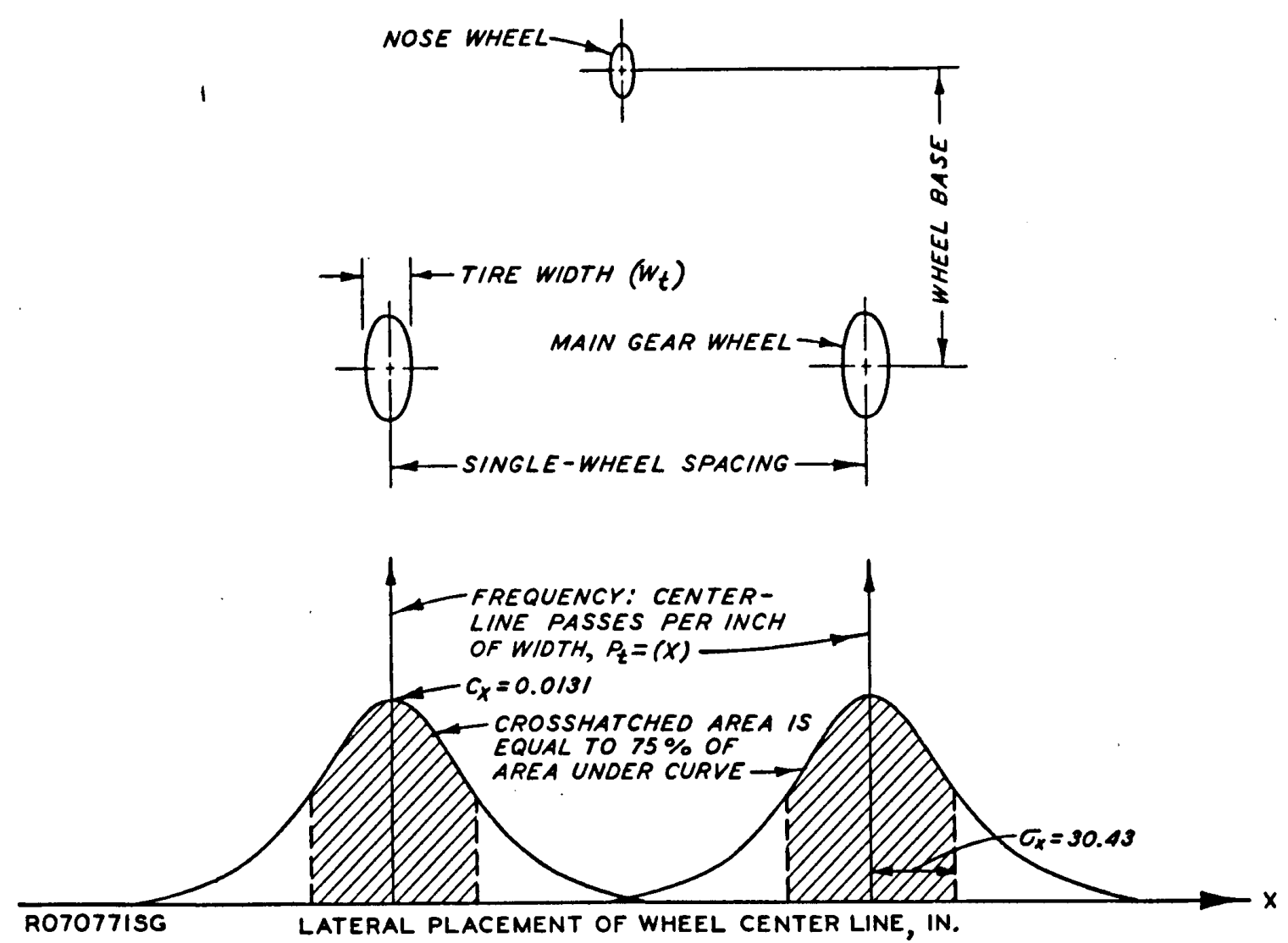

Fig. 12. General normal distribution for nonoverlapping wheels for the tricycle landing gear shown above

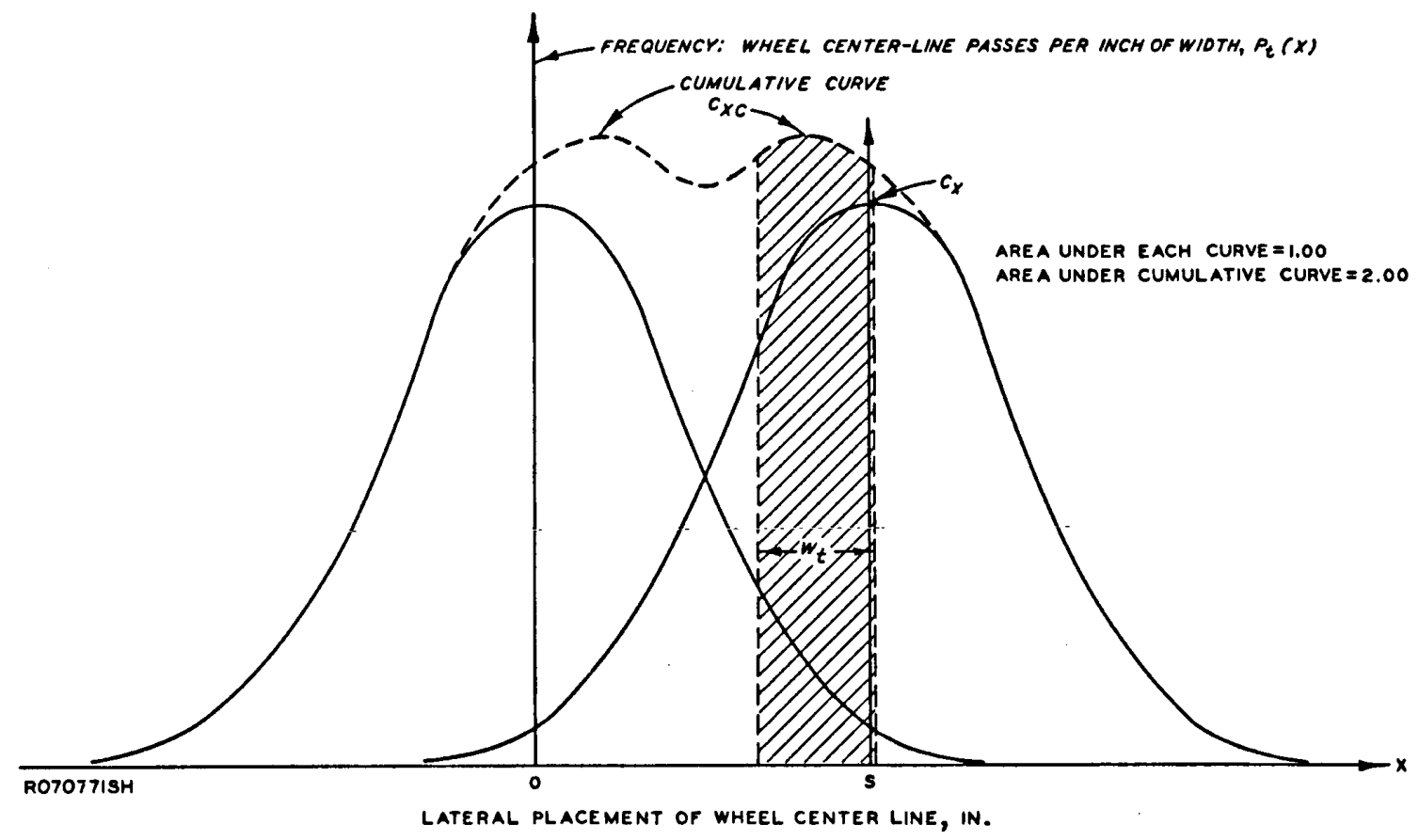

Fig. 13. General normal distribution curve for overlapping single wheel 
of the overlapping wheel path patterns gives the cumulative curve. The area under the curve equals two wheel passes or one aircraft pass as before. Now, however, the maximum coverage is the maximum area under the cumulative curve within a width of $\mathrm{W}_{t}$. This value will not necessarily occur under one wheel but must be determined in both magnitude and location. The maximum area may be as shown by the crosshatched area in fig. 13. Such a refinement is not considered warranted, and, for simplicity, the value $\left(\mathrm{C}_{\mathrm{xc}}\right)\left(\mathrm{W}_{t}\right)$ is taken as coverages. $\mathrm{C}_{\mathrm{xc}}$ must be obtained graphically. The determination of $C_{x c}$ could easily be programmed to be determined using a computer, but this has not been done since this determination need be made only one time for each aircraft. Thus

$$
\frac{p}{c}=\frac{1}{\left(c_{x c}\right)\left(w_{t}\right)}\left(\frac{a p}{w p}\right)
$$

28. As an aid in determining the maximum ordinate $\mathrm{C}_{\mathrm{xc}}$ on cumulative traffic distribution curves for two wheels, fig. 14 was drawn.

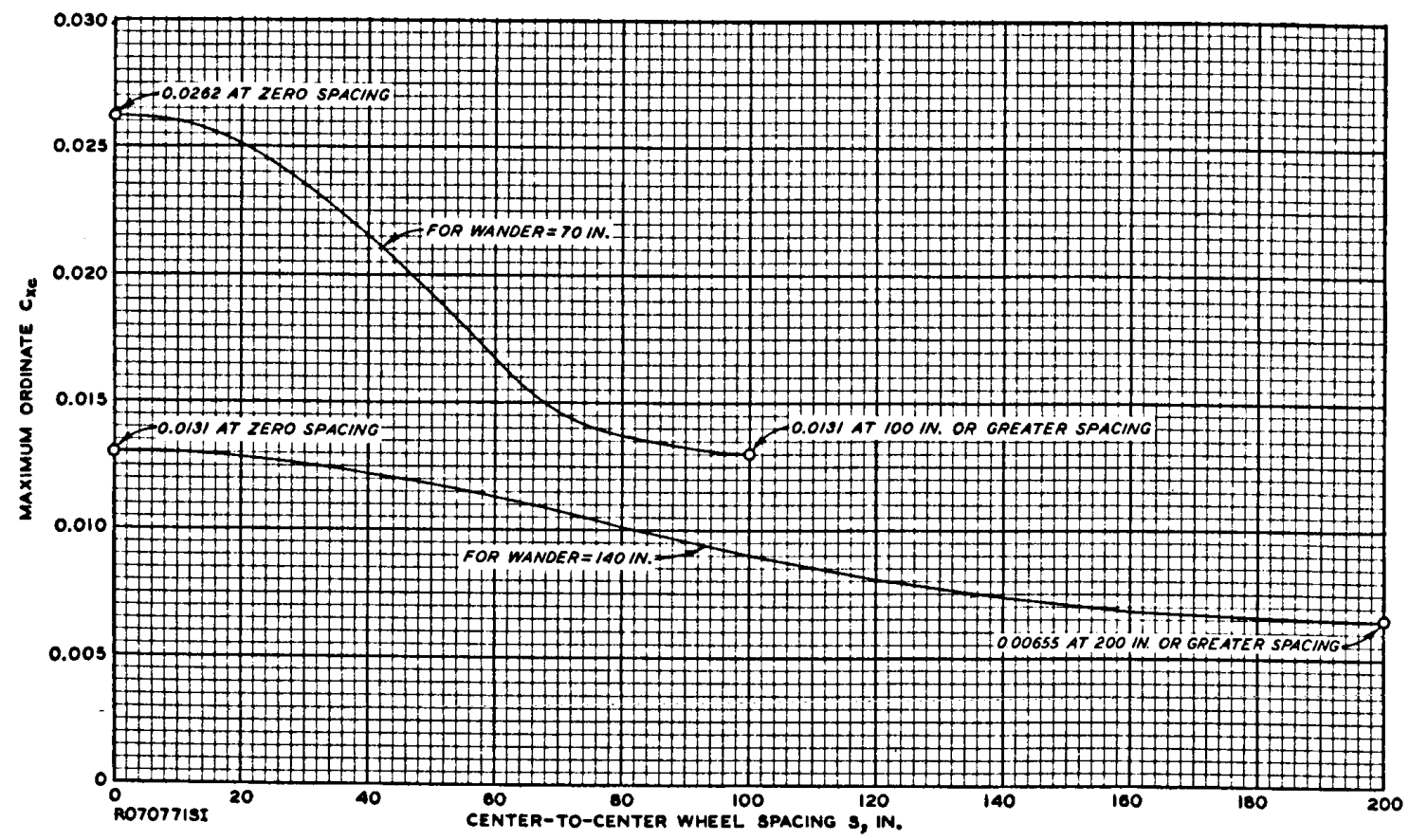

Fig. 14. Maximum ordinate on cumulative traffic distribution curve for two wheels versus wheel spacing 
This figure shows $C_{x c}$ versus wheel spacing for wander widths of 70 and 140 in. For a wander of 70 in., $C_{x c}=C_{x}=0.0131$ when the wheel spacing is greater than 100 in. (nonoverlapping wheel paths). When the wheel spacing is zero, $\mathrm{C}_{\mathrm{xc}}=2 \mathrm{C}_{\mathrm{x}}=0.0262$ (tandem assembly). When the wheel spacing is greater than zero and less than 100 in., $\mathrm{C}_{\mathrm{Xc}}$ can be read from fig. 14. For a wander of 140 in., $C_{x c}=C_{x}=0.00655$ when the wheel spacing is greater than 200 in. (nonoverlapping wheel paths). When the wheel spacing is zero, $C_{x c}=2 C_{x}=0.0131$ (tandem assembly). When the wheel spacing is greater than zero and less than 200 in., $\mathrm{C}_{\mathrm{xc}}$ can be read from fig. 14. Fig. 14 is applicable to the following gear configurations (see wheel configuration diagrams in fig. 4) without exception: single conventional, single tricycle, single-tandem tricycle,* and twin bicycle; and to the following gear configurations when the tread minus the twin-wheel spacing is greater than 100 in. (for 70-in. wander) or $200 \mathrm{in.} \mathrm{(for} \mathrm{140-in.} \mathrm{wander):} \mathrm{twin} \mathrm{conventional,} \mathrm{twin} \mathrm{tri-}$ cycle, and twin-tandem tricycle.* In all other instances (when the tread minus the single-wheel spacing is less than indicated above) and for other gear configurations, it is necessary to determine $C_{x c}$ graphically as shown for the $\mathrm{C}-5 \mathrm{~A}$ in $\mathrm{fig}$. 15 .

29. The versatility of this method is demonstrated with the determination of $\mathrm{p} / \mathrm{c}$ values for the $\mathrm{C}-5 \mathrm{~A}$ and Boeing 747 landing gear wheel configurations as shown below for a wander of 70 in.

a. The C-5A gear configuration is shown in fig. 16. The theoretical normal traffic distribution curves for the wheel groups A or B and A plus B or B plus D are shown in fig. 15. By inspection, it can be seen that the maximum ordinate for group A plus group C (or group B plus group D) is the maximum ordinate for the assembly. Thus

$$
C_{x c}=0.086\left(\frac{w p}{\text { in. }}\right)
$$

For the main gear assembly, the total number of wheel

\footnotetext{
* Note that for these gear configurations, values of $C_{X c}$ can be read directly from fig. 14 for use in calculating $\mathrm{p} / \mathrm{c}$ ratios for aircraft operating on rigid pavements. These same values of $\mathrm{C}_{\mathrm{xc}}$ are doubled for use in calculating $\mathrm{p} / \mathrm{c}$ ratios for aircraft operating on flexible pavements and landing-mat-surfaced and unsurfaced airfields.
} 


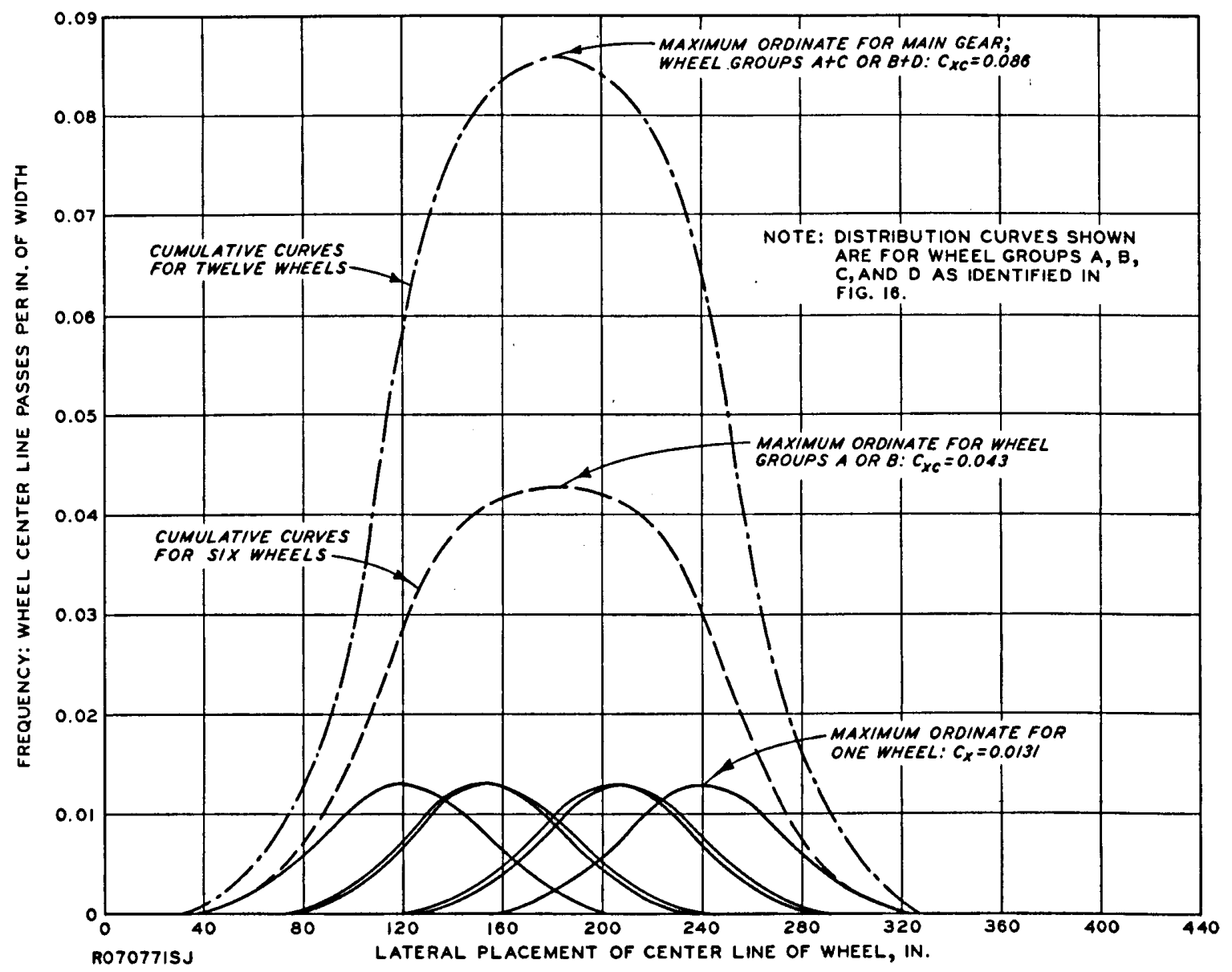

Fig. 15. Theoretical normal distribution for main gear of $\mathrm{C}-5 \mathrm{~A}$, wander $=70$ in.

passes is 24. However, 24 wheel passes equal 1 aircraft pass. Thus,

$$
\begin{aligned}
\frac{p}{c} & =\frac{1}{24}\left(\frac{a p}{w p}\right) \frac{24(w p)}{1} \frac{1}{(0.086)\left(w_{t}\right)}\left(\frac{i n}{w p}\right)\left(\frac{1}{i n .}\right) \\
& =\frac{1}{(0.086)\left(w_{t}\right)}\left(\frac{a p}{w p}\right)
\end{aligned}
$$

or, as before,

$$
\frac{p}{c}=\frac{1}{\left(c_{x c}\right)\left(w_{t}\right)}\left(\frac{a p}{w p}\right)
$$

b. The Boeing 747 wheel configuration is shown in fig. 17 . 


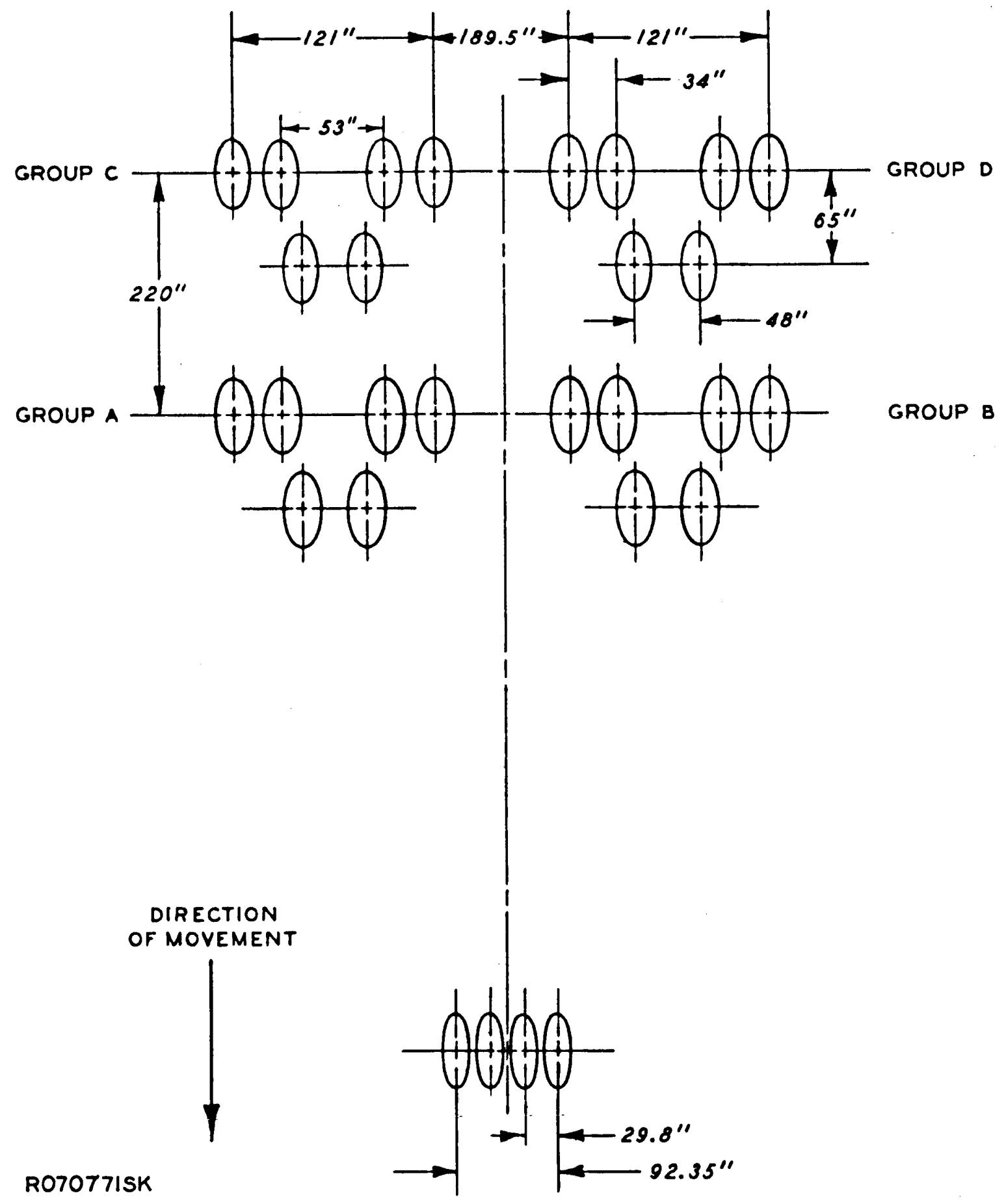

Fig. 16. C-5A gear configuration 


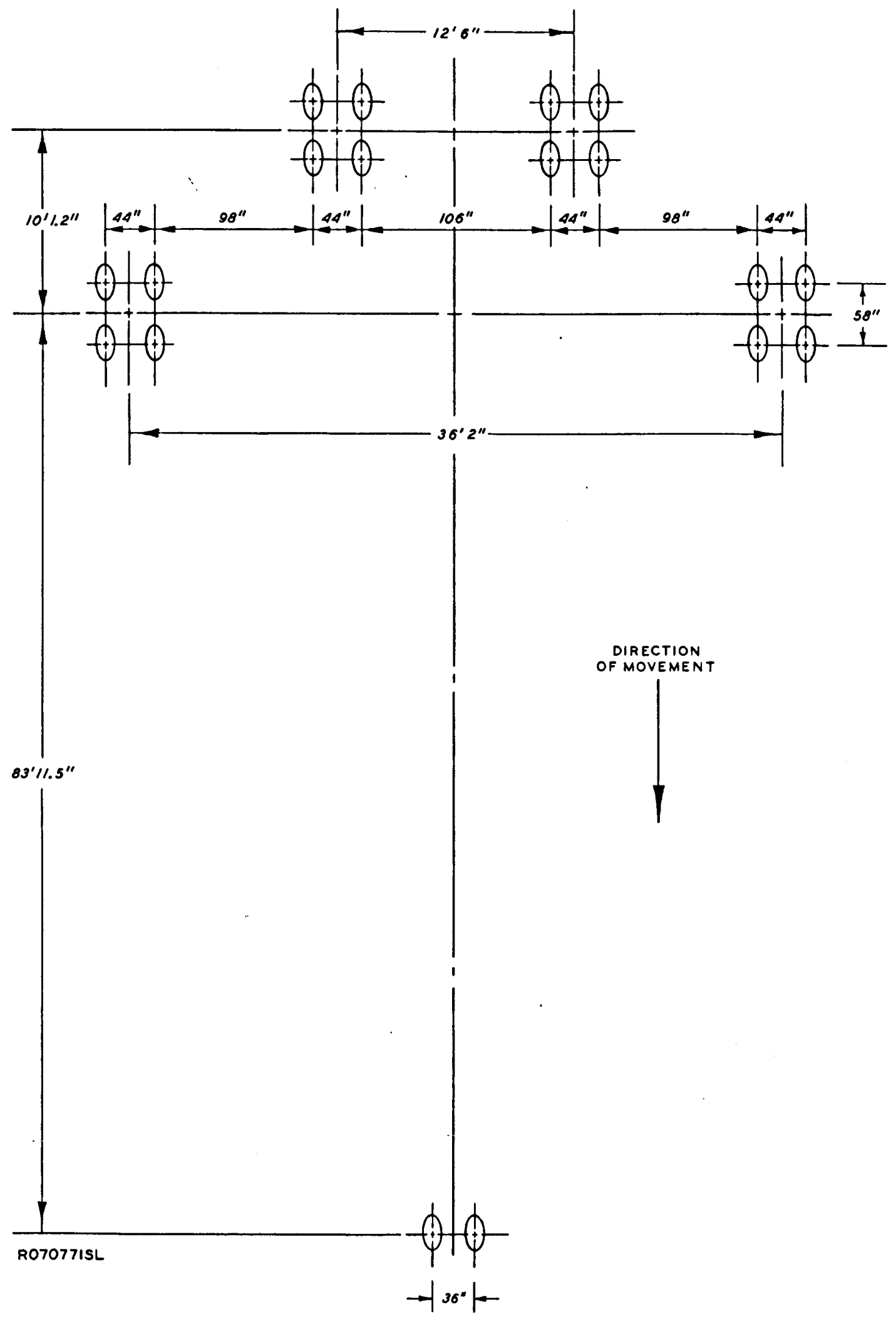

Fig. 17. Boeing 747 gear configuration 
The theoretical normal traffic distribution curve for one-half the main gear is shown in fig. 18. The maximum ordinate on this curve is 0.042 resulting from one of the four twin-tandem assemblies. Thus, by inspection it can be seen that the maximum ordinate for the 747 assembly will be that resulting from one twin-tandem assembly where:

$$
c_{x c}=0.042
$$

This value could have been estimated, with reasonable accuracy, through use of fig. 14 since the minimum spacing between twin-tandem assemblies is approximately 100 in. For the main gear assembly, the total number of wheel passes is 16; however, 16 wheel passes equal 1 aircraft pass. Thus,

$$
\begin{aligned}
& \frac{p}{c}=\frac{1}{16}\left(\frac{a p}{w p}\right) 16(w p) \frac{1}{(0.042)\left(w_{t}\right)}\left(\frac{i n .}{w p}\right) \text { (in.) } \\
& \frac{p}{c}=\frac{1}{(0.042)\left(w_{t}\right)}\left(\frac{a p}{w p}\right)
\end{aligned}
$$

and, as before,

$$
\frac{p}{c}=\frac{I}{\left(c_{x c}\right)\left(w_{t}\right)}\left(\frac{a p}{w p}\right)
$$

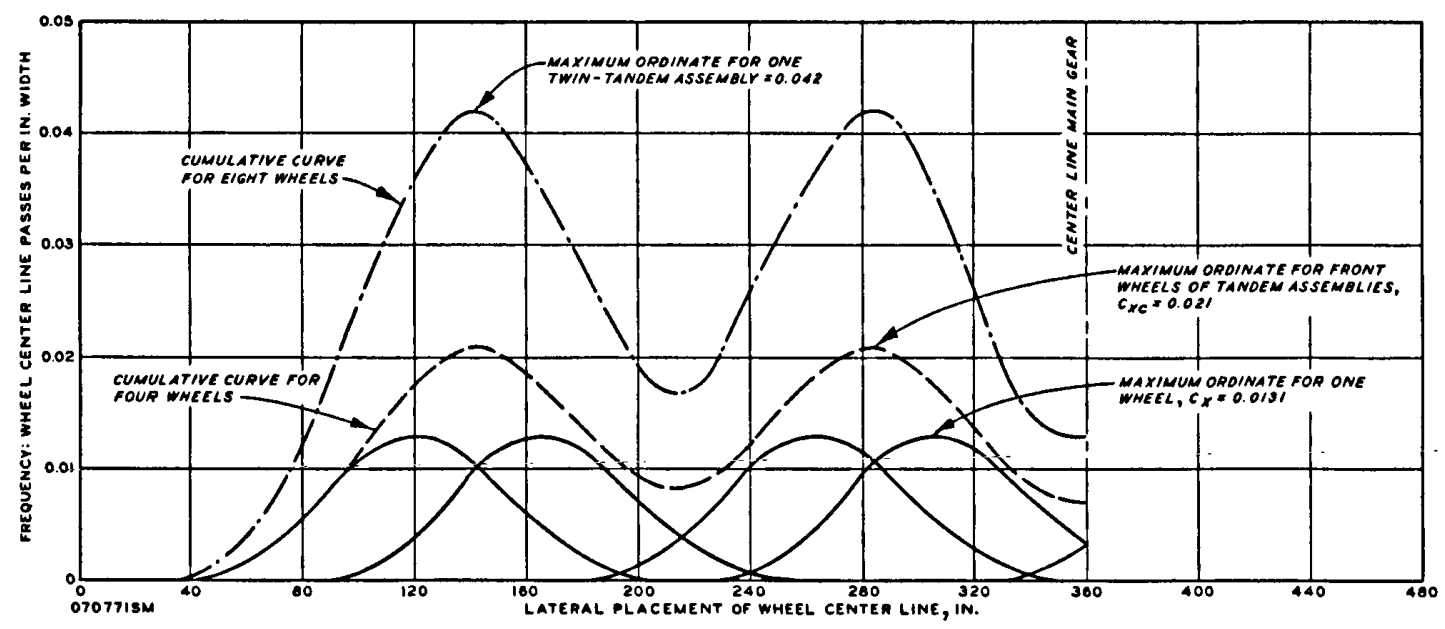

Fig. 18. Theoretical normal distribution for main gear of Boeing 747, wander $=70$ in. 
PART IV: COMPARISON OF METHODS OF DETERMINING PASS/COVERAGE VALUES

30. In Part II, the current method for determining $\mathrm{p} / \mathrm{c}$ ratios is presented (equation 7); in Part III, a theoretical method for determining $\mathrm{p} / \mathrm{c}$ ratios is presented (equations 11 and 12 ). In this part, values obtained using the two methods are compared for common aircraft in service in 1971. Both military and civilian aircraft are included.

31. A listing of the relevant dimensions of current aircraft is given in table 1. In many cases, a particular aircraft has been produced in various models with slightly different dimensions from those listed. However, the values in table 1 are considered representative since small changes in physical dimensions are of no significant consequence. The diagrams in figs. 4, 16, and 17 depict the types of gear configurations considered in table 1.

32. In Part II, reference is made to studies in which actual traffic distribution patterns were developed from an analysis of field traffic distribution data obtained from observations of the operation of specific aircraft at several locations along taxiways and runways at various Air Force bases. ${ }^{4,5}$ These traffic distribution patterns for $\mathrm{B}-47, \mathrm{KC}-97, \mathrm{~B}-52$, and $\mathrm{KC}-135$ aircraft are shown in graphic form as traffic distribution curves (solid lines) in fig. 5 and plates 1-1l. These data represent the total information presently available relative to actual lateral traffic distribution of aircraft operating on airfield pavements at military installations.

33. Theoretical normal traffic distribution curves (dashed lines) are also shown in fig. 5 and plates l-ll for all aircraft considered and at all locations where actual traffic distribution data were available. These traffic distribution curves are based on computed values calculated in such a manner that the maximum ordinate on each theoretical traffic distribution curve is equal or approximately equal to the maximum ordinate on each actual traffic distribution curve. The theoretical wander used in each case is given in table 2.

34. The comparison of actual and theoretical normal traffic 
distribution curves along straightways of taxiways shown for the B-47 and $\mathrm{KC}-97$ in fig. 5 indicates that a theoretical wander of $70 \mathrm{in}$. is representative of observed traffic distribution along straightways of taxiways. Similar comparisons, shown in plates 1-3, for taxiway curves indicate that a variable theoretical wander (32-95 in.) is required to represent observed traffic distribution along taxiway curves. Since the Corps of Engineers has been designing pavements along both straightways and curves on taxiways for the same traffic distribution pattern for many years and no indication has ever been noted that the service life of pavements along taxiway curves has been materially different from that of pavements along straightways on taxiways, a theoretical wander of 70 in. has been selected for use in this study as the best value for representation of actual observed traffic distribution along taxiways.

35. The comparisons of actual observed and theoretical traffic distribution curves for the $\mathrm{B}-47, \mathrm{KC}-97, \mathrm{~B}-52$, and $\mathrm{KC}-135$ aircraft along runways, shown in plates 4-11, indicate that the theoretical wander required to represent actual traffic distribution varies with type of aircraft and location of aircraft along the runway. This observation is in agreement with service behavior records for airfield pavements. Calculated values for the theoretical wander required to best represent actual traffic distribution, shown in table 2, are presented in graphic form in fig. 19. This plot shows the variation in theoretical wander along runways for the $\mathrm{B}-47, \mathrm{KC}-97, \mathrm{~B}-52$, and $\mathrm{KC}-135$ aircraft. It is not considered practical at the present time to attempt to design runway pavements for continuously changing traffic distribution patterns, as indicated by the solid curves in fig. 19; therefore, on the basis of the data shown in fig. 19, a theoretical wander of 70 in. has been selected as the best value for representation of actual traffic distribution along the first $1000 \mathrm{ft}$ at each end of a runway, and a theoretical wander of $140 \mathrm{in.} \mathrm{has} \mathrm{been} \mathrm{selected} \mathrm{as} \mathrm{the} \mathrm{best} \mathrm{balue} \mathrm{for} \mathrm{representation}$ of actual traffic distribution along the interior portions of runways, as indicated by the dashed lines in fig. 19. The Corps of Engineers has recognized that traffic distribution patterns vary along taxiways and runways and have zoned their pavements for thickness design on the 


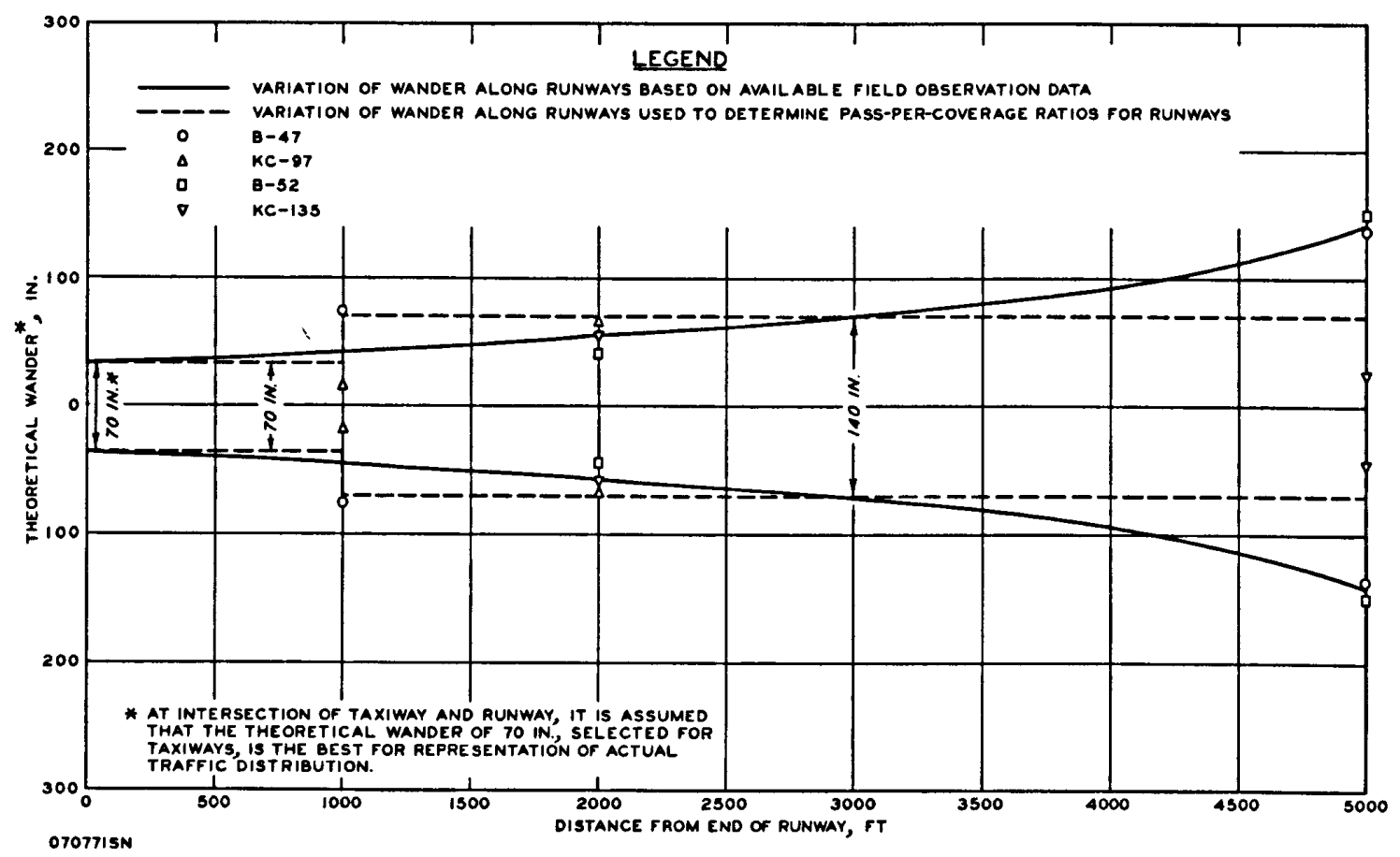

Fig. 19. Variation in theoretical wander along runways

basis of variable traffic distribution. 9

36. Pass-per-coverage ratios have been calculated using equations 7 and 12 for uniform, theoretical, and actual traffic distribution. These $\mathrm{p} / \mathrm{c}$ ratios are shown in columns 4,5 , and 6 of table 3. Values shown in column 4 were calculated through use of equation 7 using a 40-in. wander in accordance with current practice. Values shown in column 5 were calculated through use of equation 12 using a wander of 70 in. for taxiways and $140 \mathrm{in.} \mathrm{for} \mathrm{runways} \mathrm{as} \mathrm{proposed} \mathrm{herein.} \mathrm{Values}$ shown in column 6 were calculated through use of equation 12 using the theoretical wander values shown in table 2 . The relation between $p / c$ ratios based on uniform and actual traffic distribution is shown in column 7 of table 3. As can be seen, $p / c$ ratios based on uniform traffic distribution do not agree very well with $p / c$ ratios based on actual traffic distribution. The implication of this observation is significant. For instance, using the B-47, the current basic design of 5000 coverages represents $10,650(2.13 \times 5000)$ aircraft passes for uniform traffic distribution, but 5000 coverages represent from 7750 ( $1.55 \times 5000)$ 
to $26,300(5.26 \times 5000)$ aircraft passes for actual traffic distribution. Whereas it is currently assumed that pavements designed for 5000 coverages will sustain 10,650 aircraft passes before accumulation of the critical coverages (5000), it appears that, in fact, based on actual observed traffic distribution, the critical number of coverages is accumulated after 7750 or 26,300 aircraft passes, depending on the location or the airfield. Similar calculations for other aircraft will show comparable variations.

37. The reason for a wide variation between $\mathrm{p} / \mathrm{c}$ ratios based on uniform and actual traffic distribution is shown in fig. 20, where the actual and theoretical normal traffic distribution curves determined through use of equation 12 for a B-47 on straightways of taxiways have been superimposed on a uniform traffic distribution diagram determined through use of equation 7 for a B-47 on straightways of taxiways. Assuming the following dimensions for the B-47:

$$
\begin{aligned}
\mathrm{W}_{t} & =14.3 \mathrm{in.}=1.19 \mathrm{ft} \\
\mathrm{W} & =40 \mathrm{in} . \quad=3.33 \mathrm{ft} \\
\mathrm{S}_{t} & =37 \mathrm{in.}=\frac{3.08 \mathrm{ft}}{7.60 \mathrm{ft}}
\end{aligned}
$$

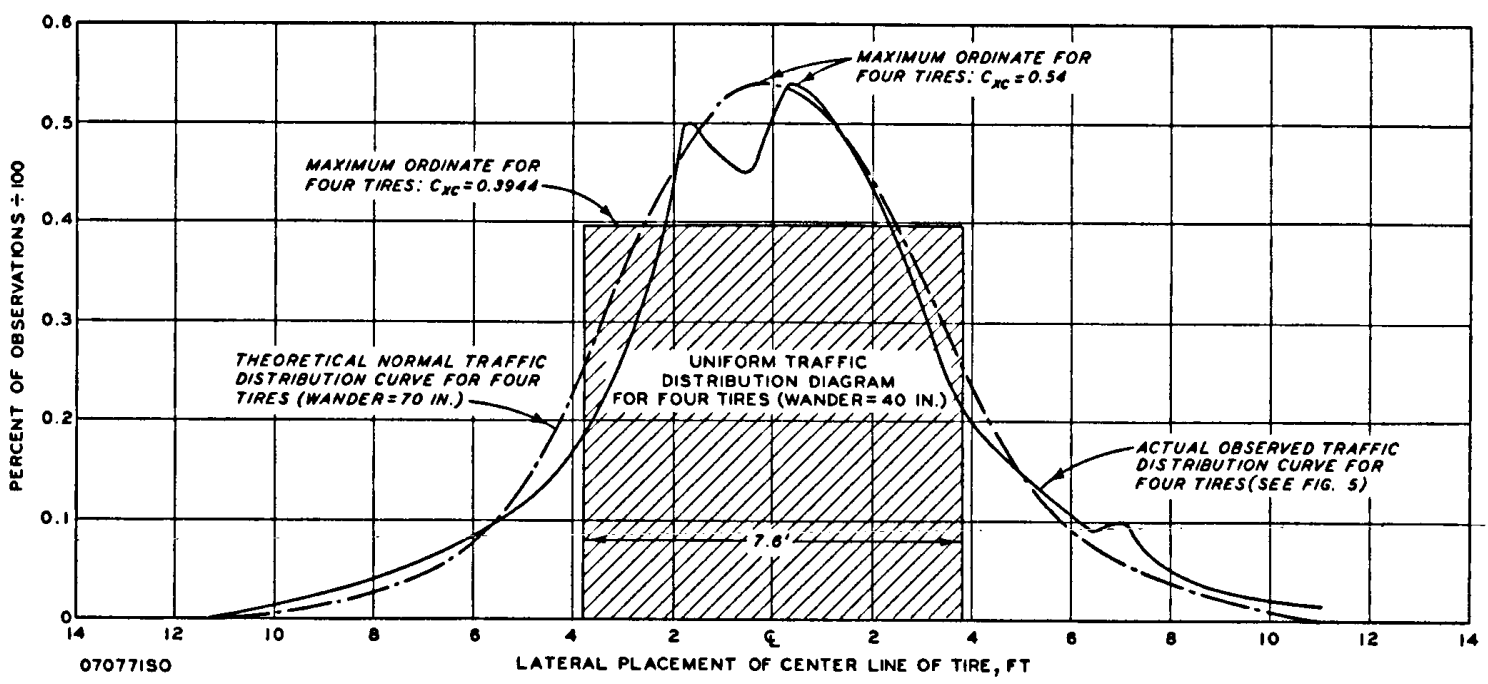

Fig. 20. Comparative plots of uniform, theoretical normal, and actual traffic distribution along straightways of taxiways for B-47 aircraft 
According to equation 7:

$$
\left(\frac{p}{c}\right)_{t}=\frac{w_{t}+S_{t}+40}{0.75(N)\left(W_{t}\right)}
$$

Therefore,

$$
\left(\frac{p}{c}\right)_{t}=\frac{1.19+3.08+3.33}{(0.75)(4)(1.19)}=2.13
$$

For the B-47, one aircraft pass generates four wheel passes. Thus, the area within the uniform traffic distribution diagram is equal to 4 units, and the area within this diagram representing 75 percent of the traffic is equal to 3 units. Therefore, the uniform traffic distribution diagram for the B-47 can be represented by a rectangular diagram with a width (abscissa) of $7.6 \mathrm{ft}$ and a height (ordinate) of:

$$
\frac{3.00}{7.6}\left(\frac{w p}{f t}\right)=0.3944\left(\frac{w p}{f t}\right)
$$

as shown in fig. 20. Using equation 12 and applying it to the uniform traffic distribution diagram shown:

$$
\frac{p}{c}=\frac{1}{\left(c_{x c}\right)\left(w_{t}\right)}
$$

where

$$
\begin{aligned}
& C_{x c}=0.3944(w p / f t) \\
& W_{t}=1.19 \mathrm{ft} \\
& \quad \frac{p}{c}=\frac{1}{(0.3944)(1.19)}=2.13 \text { as before. }
\end{aligned}
$$

Using equation 12 and applying it to the actual traffic distribution curve shown in fig. 20:

$$
\begin{aligned}
c_{x c} & =0.54\left(\frac{w p}{f^{\prime} t}\right) \\
w_{t} & =1.19 \mathrm{ft} \\
\frac{p}{c} & =\frac{1}{(0.54)(1.19)}=1.55
\end{aligned}
$$


and the ratio between $\mathrm{p} / \mathrm{c}$ ratios for uniform and actual traffic distribution is:

$$
\frac{2.13}{1.55}=1.37
$$

38. Similar calculations may be made to show the variation in $\mathrm{p} / \mathrm{c}$ ratios based on theoretical normal and actual traffic distribution patterns. Results of these calculations are shown in column 8 of table 3. Examination of resulting relations between $p / c$ ratios based on theoretical and actual traffic distribution patterns shows that considerably better agreement exists between these $\mathrm{p} / \mathrm{c}$ ratios than between $\mathrm{p} / \mathrm{c}$ ratios for uniform and actual traffic distribution except in two instances, KC-97 aircraft $1000 \mathrm{ft}$ from the runway end and KC-135 $5000 \mathrm{ft}$ from the runway end. It is inconceivable that the $\mathrm{KC}-97$ or the $\mathrm{KC}-135$ will consistently operate within the narrow limits indicated by the actual traffic distribution shown for these aircraft in plates 6 and 11 . If these actual traffic distribution curves are not considered, then the $\mathrm{p} / \mathrm{c}$ ratios based on theoretical normal traffic distribution are in better agreement with the $\mathrm{p} / \mathrm{c}$ ratios based on actual traffic distribution than $\mathrm{p} / \mathrm{c}$ ratios based on uniform traffic distribution. It is on this basis that it is suggested that the basis for determining $\mathrm{p} / \mathrm{c}$ ratios be changed from uniform traffic distribution, as presently used, to theoretical normal traffic distribution. Adoption of procedures discussed herein, based on theoretical normal traffic distribution for a wander of $70 \mathrm{in}$. on taxiways and $140 \mathrm{in}$. on runways, will provide improved procedures for calculating $\mathrm{p} / \mathrm{c}$ ratios representative of actual traffic distribution.

39. In accordance with the suggestion made above, $p / c$ ratios have been computed for various aircraft now operating at both civilian and military airfields. These $\mathrm{p} / \mathrm{c}$ ratios for taxiways (wander $=70$ in.) and runways (wander $=140$ in.) are given in tables 4 and 5. 


\section{Conclusions}

40. Two conclusions can be drawn from this study. First, and most important, it is unmistakably clear that considerably more field traffic data are required, particularly with reference to current aircraft, before any further progress can be made in the development of $\mathrm{p} / \mathrm{c}$ ratios that are truly representative of actual traffic distribution patterns. Secondly, adoption of the theoretical normal traffic distribution curves as a basis for development of $\mathrm{p} / \mathrm{c}$ ratios will provide an improved and more realistic procedure for determining $\mathrm{p} / \mathrm{c}$ ratios that will, in general, be more representative of actual traffic distribution than similar ratios based on uniform traffic distribution.

\section{$\underline{\text { Recommendations }}$}

41. It is recommended that the $\mathrm{p} / \mathrm{c}$ ratios given in tables 4 and 5 be adopted for use in converting test section traffic in terms of coverages into equivalent aircraft traffic in terms of aircraft passes until such time as additional field traffic data become available for further studies.

42. Investigations should be made that will provide information on the influence of factors such as the random placement of traffic across the width of a runway or taxiway, the variation of load intensity and contact pressure of the tires of a multiple-wheel gear, and the variation of loading conditions of the main and nose gears of an aircraft. The following studies are recommended.

a. Airfield surveys to determine the actual lateral and longitudinal distribution of traffic for all types of aircraft.

b. Studies to determine the percentage of operations for each type of aircraft expected to operate on a pavement for design or the percentage of operations for each type of aircraft that has been on a pavement for evaluation. Then the traffic could be accumulated graphically. 
c. Studies to determine the detrimental effects of a wheel at various distances from the point of maximum accumulation of repetitions and then develop a location weighting function $\alpha_{i}$ to be applied to traffic repetitions. 
1. U. S. Army Engineer District, Sacramento, CE, "Report of Stockton Runway Test Section," 1942, Sacramento, Calif.

2. U. S. Army Engineer District, Little Rock, CE, "Service Behavior Test Section, Barksdale Field, La.," Oct 1944, Little Rock, Ark.

3. U. S. Army Engineer Waterways Experiment Station, CE, "Collection of Letter Reports on Flexible Pavement Design Curves," Miscellaneous Paper No. 4-61, Jun 1951, Vicksburg, Miss.

4. , "Study of Channelized Traffic," Technical Memorandum No. 3-426, Feb 1956, Vicksburg, Miss.

5. Vedros, P. J., "Study of Lateral Distribution of Aircraft Traffic on Runways," Miscellaneous Paper No. 4-369, Jan 1960, U. S. Army Engineer Waterways Experiment Station, $\mathrm{CE}$, Vicksburg, Miss.

6. U. S. Air Force Systems Command, "Aircraft Ground Flotation Analysis Paved Airfields," Technical Report SEG-TR-67-52, Apr 1968, WrightPatterson Air Force Base, Ohio.

7. Federal Works Agency, Works Projects Administration, "Tables of Probability Functions," Vol II, 1942, New York, N. Y.

8. Hay, D. R., "Aircraft Characteristics for Airfield Pavement Design and Evaluation," Technical Report No. AFWL-TR-69-54, Oct 1969, Kirtland Air Force Base, N. Mex.

9. Headquarters, Department of the Army, "General Provisions for Airfield Design, Airfields Other Than Army," Technical Manual No. TM 5-824-1, Dec 1965, Washington, D. C. 
Table 1

Typical Aircraft Landing Gear Characteristics

\begin{tabular}{|c|c|c|c|c|c|c|c|}
\hline $\begin{array}{c}\text { Type Landing Gèar } \\
\text { and Aircraft }\end{array}$ & $\begin{array}{c}\text { Tire } \\
\text { Inflation } \\
\text { Pressure } \\
\text { lb/in.2 } \\
\end{array}$ & $\begin{array}{c}\text { Tire } \\
\text { Contact } \\
\text { Area } \\
\text { in. } \\
\end{array}$ & $\begin{array}{l}\text { Tire } \\
\text { Width } \\
w_{\mathrm{t}} \\
\text { in. } \\
\end{array}$ & $\begin{array}{l}\text { Wheel } \\
\text { Base } \\
W_{b} \\
\text { in. }\end{array}$ & $\begin{array}{l}\text { Tread } \\
\mathrm{T}_{\mathrm{W}} \\
\text { in. }\end{array}$ & $\begin{array}{l}\text { Twin } \\
\text { Wheel } \\
\text { Spacing } \\
S_{t} \\
\text { in. }\end{array}$ & $\begin{array}{l}\text { Tandem } \\
\text { Wheel } \\
\text { Spacing } \\
\mathrm{S}_{\mathrm{m}} \\
\text { in. }\end{array}$ \\
\hline \multicolumn{8}{|c|}{ Civilian Aircraft* } \\
\hline $\begin{array}{l}\text { Twin tricycle } \\
\text { Boeing 727-00 } \\
\text { Boeing } 723-200 \\
\text { DC-9-30 }\end{array}$ & $\begin{array}{l}170 \\
130 \\
145\end{array}$ & $\begin{array}{l}236 \\
170 \\
168\end{array}$ & $\begin{array}{l}13.5 \\
13.5 \\
11.5\end{array}$ & $\begin{array}{l}639 \\
448 \\
638\end{array}$ & $\begin{array}{l}225 \\
206 \\
197\end{array}$ & $\begin{array}{l}34 \\
34 \\
25\end{array}$ & \\
\hline $\begin{array}{l}\text { Twin-tandem tricycle } \\
\text { Boeing } 707-100 \\
\text { DC-8-10 } \\
\text { DC-10-1.0, } 20 \\
\text { Convair } 880\end{array}$ & $\begin{array}{l}180 \\
155 \\
176 \\
150\end{array}$ & $\begin{array}{l}236 \\
228 \\
276 \\
152\end{array}$ & $\begin{array}{l}13.5 \\
13.5 \\
15.0 \\
11.0\end{array}$ & $\begin{array}{l}628 \\
692 \\
868.5 \\
637\end{array}$ & $\begin{array}{l}265 \\
250 \\
420 \\
226\end{array}$ & $\begin{array}{l}34 \\
30 \\
54 \\
22.5\end{array}$ & $\begin{array}{l}56 \\
55 \\
64 \\
45\end{array}$ \\
\hline $\begin{array}{l}\text { Multiple-wheel tricycle } \\
\text { Boeing } 747\end{array}$ & 200 & $\begin{array}{l}208 \\
\text { litary Ai }\end{array}$ & $\begin{array}{r}12.9 \\
\text { craft* }\end{array}$ & - & - See & fig. 17 & \\
\hline $\begin{array}{l}\text { Single tricycle } \\
\text { A-7D } \\
A-26 \mathrm{~A} \\
\mathrm{~B}-57 \mathrm{~B} \\
\mathrm{C}-123 \mathrm{~K} \\
\mathrm{~F}-104 \mathrm{G} \\
\mathrm{F}-4 \mathrm{E} \\
\mathrm{F}-11 \mathrm{~A}\end{array}$ & $\begin{array}{r}280 \\
70 \\
152 \\
92 \\
208 \\
265 \\
150\end{array}$ & $\begin{array}{r}62 \\
262 \\
182 \\
275 \\
63 \\
102 \\
313\end{array}$ & $\begin{array}{r}6.9 \\
14.2 \\
11.8 \\
14.6 \\
6.9 \\
8.9 \\
15.5\end{array}$ & $\begin{array}{l}188 \\
161 \\
171 \\
288 \\
181 \\
279 \\
288\end{array}$ & $\begin{array}{l}114 \\
233 \\
188 \\
151 \\
106 \\
215 \\
120\end{array}$ & & \\
\hline $\begin{array}{l}\text { Twin tricycle } \\
\text { C-7A } \\
\text { C-8A } \\
\mathrm{C}-54 \mathrm{G} \\
\mathrm{KC}-97 \\
\mathrm{C}-124 \mathrm{C} \\
\mathrm{C}-140 \mathrm{~A}\end{array}$ & $\begin{array}{r}115 \\
38 \\
77 \\
183 \\
79 \\
205\end{array}$ & $\begin{array}{r}272 \\
218 \\
250 \\
227 \\
640 \\
43\end{array}$ & $\begin{array}{r}14.4 \\
12.9 \\
13.8 \\
13.2 \\
22.1 \\
5.7\end{array}$ & $\begin{array}{l}251 \\
335 \\
329 \\
437 \\
357 \\
248\end{array}$ & $\begin{array}{l}277 \\
336 \\
296 \\
342 \\
410 \\
148\end{array}$ & $\begin{array}{l}20 \\
23 \\
28 \\
37 \\
44 \\
14.5\end{array}$ & \\
\hline $\begin{array}{l}\text { Single-tandem tricycle } \\
\text { C- } 130 \\
\mathrm{HC}-130 \mathrm{H}\end{array}$ & $\begin{array}{r}80 \\
115\end{array}$ & $\begin{array}{l}400 \\
364\end{array}$ & $\begin{array}{l}17.5 \\
16.7\end{array}$ & $\begin{array}{l}388 \\
388\end{array}$ & $\begin{array}{l}172 \\
172\end{array}$ & & $\begin{array}{l}60 \\
60\end{array}$ \\
\hline $\begin{array}{l}\text { Twin bicycle } \\
\text { B- } 47\end{array}$ & 195 & 267. & 14.3 & 531 & 436 & 37 & \\
\hline $\begin{array}{l}\text { Twin-twin bicycle } \\
\text { B-52 }\end{array}$ & 248 & 267 & 14.3 & 597 & 99 & 37 & \\
\hline $\begin{array}{l}\text { Twin-tandem tricycle } \\
\text { C-135A } \\
\text { KC-135A } \\
\text { C-141A }\end{array}$ & $\begin{array}{l}130 \\
155 \\
180\end{array}$ & $\begin{array}{l}261 \\
230 \\
208\end{array}$ & $\begin{array}{l}14.2 \\
13.3 \\
12.6\end{array}$ & $\begin{array}{l}548 \\
548 \\
636\end{array}$ & $\begin{array}{l}265 \\
265 \\
210\end{array}$ & $\begin{array}{l}36 \\
36 \\
32.5\end{array}$ & $\begin{array}{l}60 \\
60 \\
48\end{array}$ \\
\hline $\begin{array}{l}\text { Multiple-wheel tricycle } \\
\text { C-5A }\end{array}$ & 105 & 285 & 15.1 & & & fig. 16 & $\longrightarrow$ \\
\hline
\end{tabular}

* Values shown for civilian aircraft were obtained from manufacturer of particular aircraft. Practically all values shown for military aircraft were obtained from reference 8 . 
Table 2

Theoretical Wander Used in Computing

Data for Theoretical Normal Traffic

Distribution Curves

\begin{tabular}{|c|c|c|c|}
\hline Aircraft & Facility & Location & $\begin{array}{l}\text { Theoretical } \\
\text { Wander, in.* }\end{array}$ \\
\hline$B-47$ & $\begin{array}{l}\text { Taxiway } \\
\text { Runway }\end{array}$ & $\begin{array}{l}\text { Straightways } \\
\text { Curves } \\
1000 \text { ft from end } \\
5000 \text { ft from end }\end{array}$ & $\begin{array}{c}70 \\
32,95 \\
150 \\
275\end{array}$ \\
\hline $\mathrm{KC}-97$ & $\begin{array}{l}\text { Taxiway } \\
\text { Runway }\end{array}$ & $\begin{array}{l}\text { Straightways } \\
\text { Curves } \\
1000 \text { ft from end } \\
2000 \text { ft from end }\end{array}$ & $\begin{array}{r}70 \\
65 \\
37 \\
136\end{array}$ \\
\hline$B-52$ & Runway & $\begin{array}{l}2000 \text { ft from end } \\
5000 \text { ft from end }\end{array}$ & $\begin{array}{l}87 \cdot 5 \\
300\end{array}$ \\
\hline $\mathrm{KC}-135$ & Runway & $\begin{array}{l}2000 \text { ft from end } \\
5000 \text { ft from end }\end{array}$ & $\begin{array}{r}115 \\
90\end{array}$ \\
\hline
\end{tabular}


Table 3

Pass-Per-Coverage Ratios for Various Wander Widths

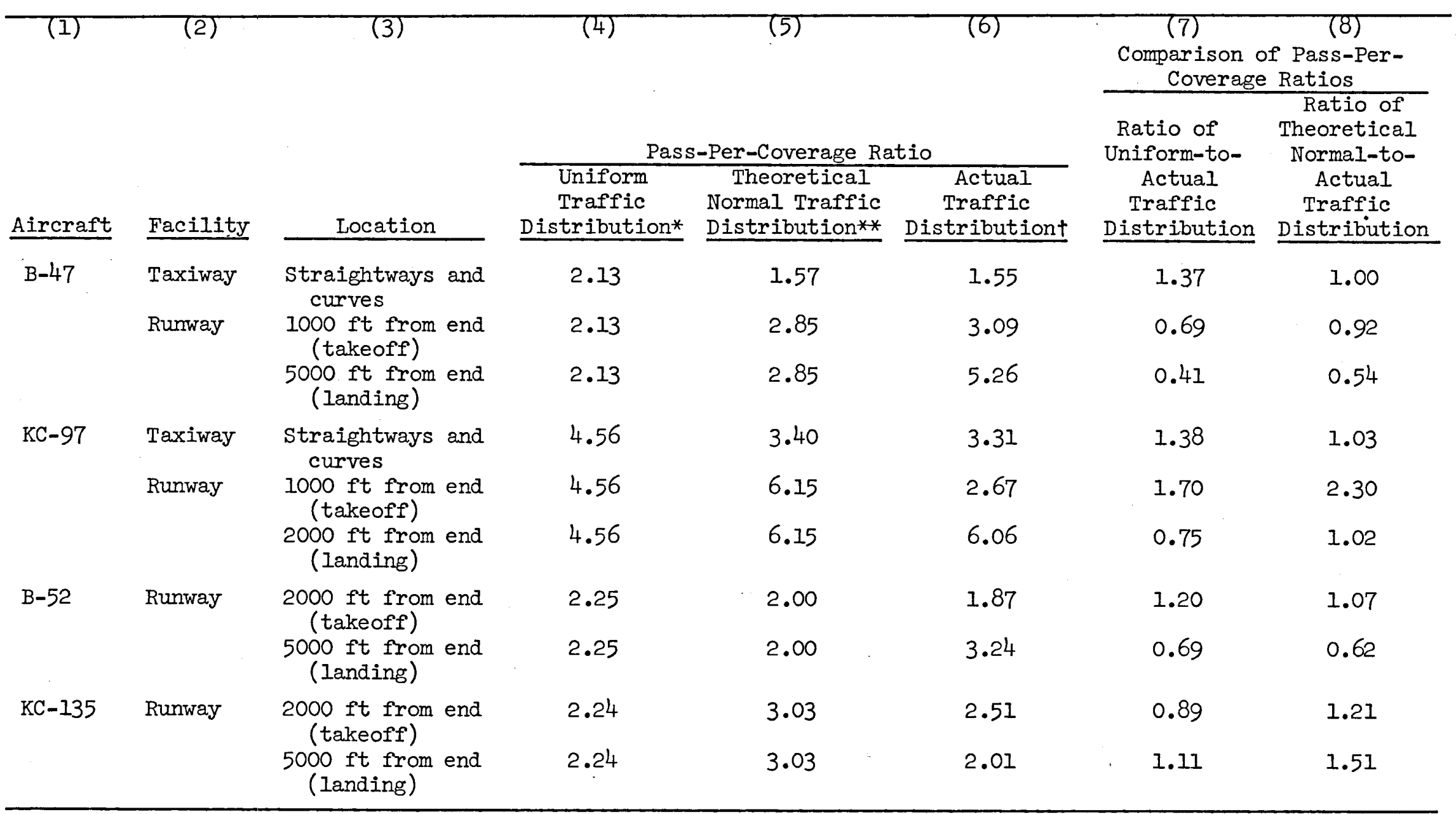

* Calculated using equation 7 with values based on 40-in. wander (current procedure).

* Calculated using equation 12 with values based on 70-in. wander for taxiways and 140-in. wander for runways (proposed procedure).

+ Calculated using equation 12 with values based on wander values given in table 2 . 


\begin{tabular}{|c|c|c|c|c|c|c|}
\hline Aircraft & $\begin{array}{l}\text { (2) } \\
\text { Twin } \\
\text { Wheel } \\
\text { Spacing } \\
\text { St }_{\mathrm{t}} \\
\text { in. } \\
\end{array}$ & $\begin{array}{l}\text { (3) } \\
\text { Tire } \\
\text { Width } \\
\text { w }_{\mathrm{t}} \\
\text { in. } \\
\end{array}$ & $\begin{array}{l}\text { (4) } \\
\text { No. of } \\
\text { Main Gear } \\
\text { Wheels in } \\
\text { Traffic } \\
\text { Lane N** } \\
\end{array}$ & $\frac{p}{c}=\frac{w_{t}+s+40 \text { in.** }}{(0.75)(\mathrm{N})\left(w_{t}\right)}$ & $\begin{array}{c}\mathrm{C}_{\mathrm{x}} \text { or } \\
\mathrm{C}_{\mathrm{xc}}{ }^{\dagger} \\
\end{array}$ & $\begin{array}{l}\frac{p}{c}=\frac{1}{\left(c_{x} \text { or } c_{x c}\right)\left(w_{t}\right)} \\
\text { Equation } 11 \text { or } 12\end{array}$ \\
\hline Boeing $727-\infty$ & 34. & 13.5 & 2 & 4.32 & 0.0228 & 3.25 \\
\hline Boeing 723-200 & 34 & 13.5 & 2 & 4.32 & 0.0228 & 3.25 \\
\hline$D C-9-30$ & 25 & 11.5 & 2 & 4.43 & 0.0243 & 3.58 \\
\hline Boeing 707-100 & 34 & 13.5 & 4 & 2.16 & 0.0456 & $1.62+t$ \\
\hline$D C-8-10$ & 30 & 13.5 & 4 & 2.06 & 0.0472 & $1.57+t$ \\
\hline DC-10-10 & 54 & 15.0 & 4 & 2.42 & 0.0366 & $1.82+t$ \\
\hline Convair 880 & 22.5 & 11.0 & 4 & 2.23 & 0.0494 & $1.84+t$ \\
\hline Boeing 747 & $\neq$ & 12.9 & 16 & 2.69 & 0.0420 & $1.85+t$ \\
\hline$A-7 D$ & $114 \neq \neq$ & 6.9 & 1 & 9.06 & 0.0131 & 11.10 \\
\hline$A-26 A$ & $233 \neq \neq$ & 14.2 & 1 & 5.09 & 0.0131 & 5.37 \\
\hline$B-57 B$ & $188 \neq \neq$ & 11.8 & 1 & 5.85 & 0.0131 & 6.47 \\
\hline$C-123 K$ & $151 \ddagger \ddagger$ & 14.6 & 1 & 4.99 & 0.0131 & 5.23 \\
\hline $\mathrm{F}-104 \mathrm{G}$ & $106 \neq \ddagger$ & 6.9 & 1 & 9.06 & 0.0131 & 11.10 \\
\hline$F-4 E$ & 215 ‡キ & 8.9 & 1 & 7.33 & 0.0131 & 8.58 \\
\hline $\mathrm{F}-111 \mathrm{~A}$ & $120 \neq \ddagger$ & 15.5 & 2 & 4.77 & 0.0131 & 4.92 \\
\hline$C-7 \mathrm{~A}$ & 20 & 14.4 & 2 & 3.44 & 0.0250 & 2.78 \\
\hline$C-8 \mathrm{~A}$ & 23 & 12.9 & 2 & 3.92 & 0.0245 & 3.16 \\
\hline$C-54 G$ & 28 & 13.8 & 2 & 3.95 & 0.0238 & 3.05 \\
\hline KC-97 & 37 & 13.2 & 2 & 4.56 & 0.0222 & 3.41 \\
\hline$c-124 c$ & 44 & 22.1 & 2 & 3.20 & 0.0207 & 2.19 \\
\hline$C-140 \mathrm{~A}$ & 14.5 & 5.7 & 2 & 7.04 & 0.0256 & 6.85 \\
\hline$C-130$ & $172 \ddagger \neq$ & 18.3 & 2 & 2.19 & 0.0262 & $2.09+t$ \\
\hline $\mathrm{HC}-130 \mathrm{H}$ & $172 \ddagger \ddagger$ & 16.7 & 2 & 2.26 & 0.0262 & $2.29+t$ \\
\hline$B-47$ & 37 & 14.3 & 4 & 2.13 & 0.0444 & 1.57 \\
\hline$B-52$ & 37 & 13.4 & 8 & 2.25 & 0.0458 & 1.63 \\
\hline$C-135 \mathrm{~A}$ & 36 & 13.3 & 4 & 2.24 & 0.0448 & $1.68+t$ \\
\hline $\mathrm{KC}-135 \mathrm{~A}$ & 36 & 13.3 & 4 & 2.24 & 0.0448 & $1.68+t$ \\
\hline$C-141 \mathrm{~A}$ & 32.5 & 12.6 & 4 & 2.25 & 0.0462 & $1.72+t$ \\
\hline$C-5 A$ & $\neq$ & 14.3 & 12 & 1.30 & 0.0860 & $0.81+t$ \\
\hline
\end{tabular}

* For wander $=70 \mathrm{in} . ; 1000 \mathrm{ft}$ at end of each runway.

* Ignoring nose wheels.

+ Values for $C_{x}$ or $C_{x c}$ read from fig. 14 or determined by graphical procedure discussed in paragraphs $26-28$.

t+ Pass-per-coverage ratios for rigid pavement for these aircraft are equal to twice the value shown (see paragraph 2).

\# See figs. 16 or 17 .

\# Twin wheel spacing for single wheel and single-tandem wheel landing gear is equal to the tread. 
Table 5

Pass-Per-Coverage Ratios for Various Aircraft

on Interior Portion of Runways*

\begin{tabular}{|c|c|c|c|c|c|c|}
\hline Aircraft & $\begin{array}{c}\text { (2) } \\
\text { Twin } \\
\text { Wheel } \\
\text { Spacing } \\
S_{t} \\
\text { in. } \\
\end{array}$ & $\begin{array}{l}\text { (3) } \\
\text { Tire } \\
\text { Width } \\
\text { Wt }_{t} \\
\text { in. } \\
\end{array}$ & $\begin{array}{l}\text { (4) } \\
\text { No. of } \\
\text { Main Gear } \\
\text { Wheels in } \\
\text { Traffic } \\
\text { Lane N** } \\
\end{array}$ & $\frac{p}{c}=\frac{w_{t}+s+40 \text { in.** }}{(0.75)(N)\left(w_{t}\right)}$ & $\begin{array}{l}\mathrm{C}_{\mathrm{x}} \text { or } \\
\mathrm{C}_{\mathrm{xc}}{ }^{\dagger} \\
\end{array}$ & $\begin{array}{l}\frac{p}{c}=\frac{1}{\left(c_{x} \text { or } c_{x c}\right)\left(w_{t}\right)} \\
\text { Equation } 11 \text { or } 12 \\
\end{array}$ \\
\hline Boeing 727-00 & 34 & 13.5 & 2 & 4.32 & 0.0124 & 6.00 \\
\hline Boeing $723-200$ & 34 & 13.5 & 2 & 4.32 & 0.0124 & 6.00 \\
\hline$D C-9-30$ & 25 & 11.5 & 2 & 4.43 & 0.0126 & 6.90 \\
\hline Boeing 707-100 & 34 & 13.5 & 8 & 2.16 & 0.0248 & $3.00+t$ \\
\hline$D C-8-10$ & 30 & 13.5 & 8 & 2.06 & 0.0250 & $2.96+t$ \\
\hline DC- $10-10$ & 54 & 15.0 & 8 & 2.42 & 0.0230 & $2.90+t$ \\
\hline Convair 880 & 22.5 & 11.0 & 8 & 2.23 & 0.0254 & $3.58+\uparrow$ \\
\hline Boeing 747 & $\neq$ & 12.9 & 16 & 2.69 & 0.028 & $2.77+t$ \\
\hline$A-7 D$ & $114 \neq \ddagger$ & 6.9 & 1 & 9.06 & 0.0066 & 22.00 \\
\hline$A-26 A$ & $233 \neq \ddagger$ & 14.2 & $I$ & 5.09 & 0.0066 & 10.70 \\
\hline B-57B & $188 \neq \neq$ & 11.8 & 1 & 5.85 & 0.0066 & 12.83 \\
\hline$c-123 K$ & $151 \neq \neq$ & 14.6 & 1 & 4.99 & 0.0066 & 10.38 \\
\hline$F-104 G$ & $106 \neq \ddagger$ & 6.9 & 1 & 9.06 & 0.0066 & 22.00 \\
\hline$F-4 E$ & $215 \neq \neq$ & 8.9 & 1 & 7.33 & 0.0066 & 17.00 \\
\hline F-IIIA & $120 \neq \neq$ & 15.5 & 2 & 4.77 & 0.0066 & 9.80 \\
\hline$C-7 A$ & 20 & 14.4 & 2 & 3.44 & 0.0128 & 5.42 \\
\hline $\mathrm{C}-8 \mathrm{~A}$ & 23 & 12.9 & 2 & 3.92 & 0.0127 & 6.10 \\
\hline$C-54 G$ & 28 & 13.8 & 2 & 3.95 & 0.0126 & 5.75 \\
\hline $\mathrm{KC}-97$ & 37 & 13.2 & 2 & 4.56 & 0.0124 & 6.11 \\
\hline$C-124 \mathrm{C}$ & 44 & 22.1 & 2 & 3.20 & 0.0120 & 3.77 \\
\hline$C-140 \mathrm{~A}$ & 14.5 & 5.7 & 2 & 7.04 & 0.0136 & 12.89 \\
\hline$c-130$ & $172 \ddagger \neq$ & 17.5 & 4 & 2.19 & 0.01325 & $4.05+t$ \\
\hline $\mathrm{HC}-13 \mathrm{OH}$ & $172 \ddagger \neq$ & 16.7 & 4 & 2.26 & 0.01325 & $4.44+t$ \\
\hline$B-47$ & 37 & 14.3 & 4 & 2.13 & 0.0248 & 2.81 \\
\hline B-52 & 37 & 13.4 & 8 & 2.25 & 0.0374 & 2.00 \\
\hline$C-135 \mathrm{~A}$ & 36 & 13.3 & 8 & 2.24 & 0.0248 & $3.03+t$ \\
\hline $\mathrm{KC}-135 \mathrm{~A}$ & 36 & 13.3 & 8 & 2.24 & 0.0248 & $3.03+t$ \\
\hline$C-141 \mathrm{~A}$ & 32.5 & 12.6 & 8 & 2.25 & 0.025 & $3.17+t$ \\
\hline$C-5 A$ & $\neq$ & 14.3 & 24 & 1.30 & 0.0636 & $1.10+t$ \\
\hline
\end{tabular}

* For wander $=140 \mathrm{in.}$

* Ignoring nose wheels.

+ Values for $C_{X}$ and $C_{X c}$ read from fig. 14 or determined by graphical procedure discussed in paragraphs $26-28$.

tt Pass-per-coverage ratios for rigid pavement for these aircraft are equal to twice the values shown (see paragraph 2).

₹ See figs. 16 or 17 .

¥ Twin wheel spacing for single-wheel and single-tandem-wheel gear is equal to the tread. 


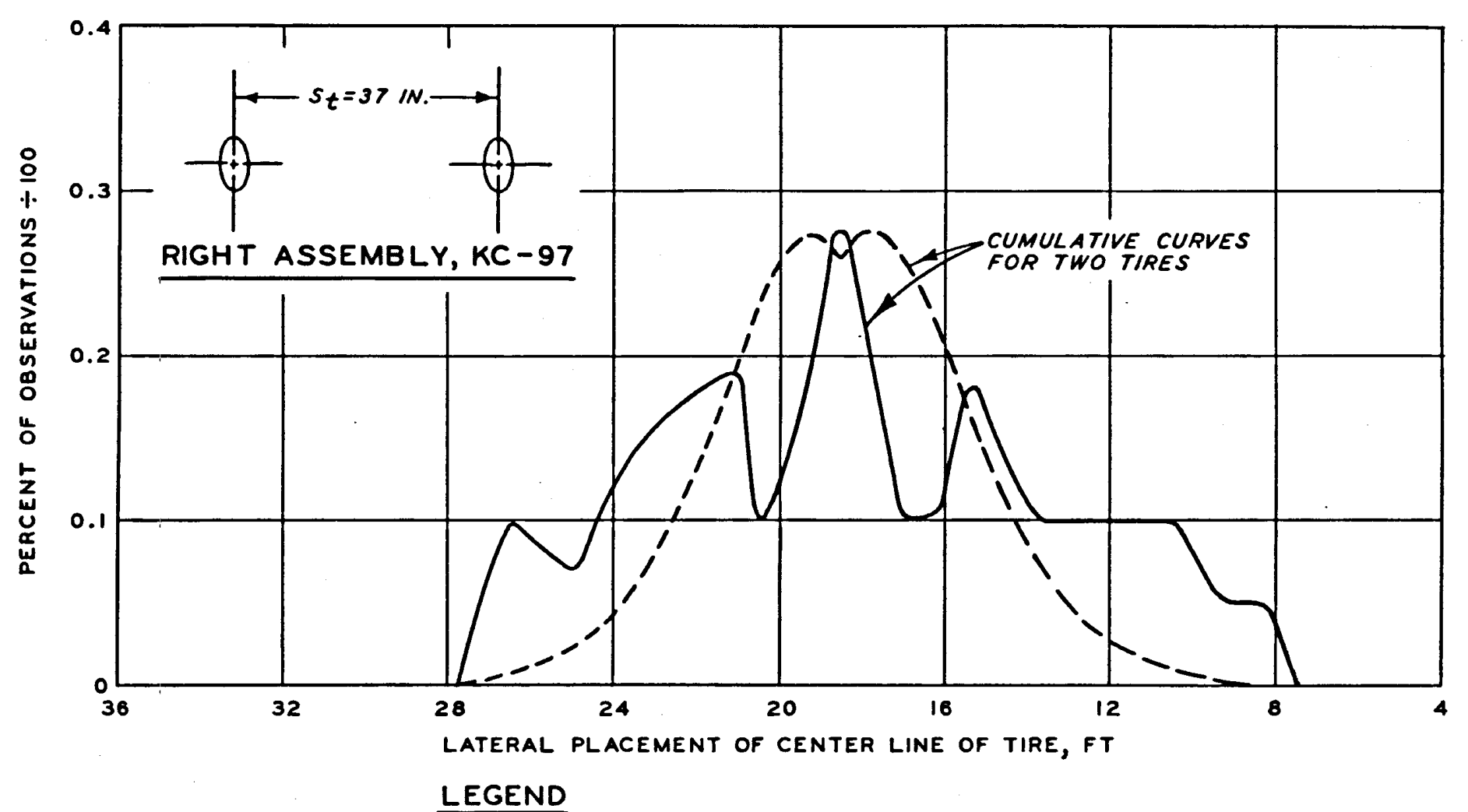

ACTUAL OBSERVED TRAFFIC DISTRIBUTION FOR

RIGHT ASSEMBLY OF KC-97 AIRCRAFT AT

POSITION 3, LINE 4, MaCDILL AIR FORCE

BASE (SEE PLATES 3 AND 7, REF 4)

- - THEORETICAL NORMAL TRAFFIC DISTRIBUTION

FOR RIGHT ASSEMBLY OF KC-97 AIRCRAFT

(WANDER = 65 IN.)

NOTE: ACTUAL OBSERVED TRAFFIC DISTRIBUTION IS BASED ON 21 OBSERVATIONS.

DISTRIBUTION OF $\mathrm{KC}-97$

AIRCRAFT TRAFFIC ON TAXIWAY CURVES 


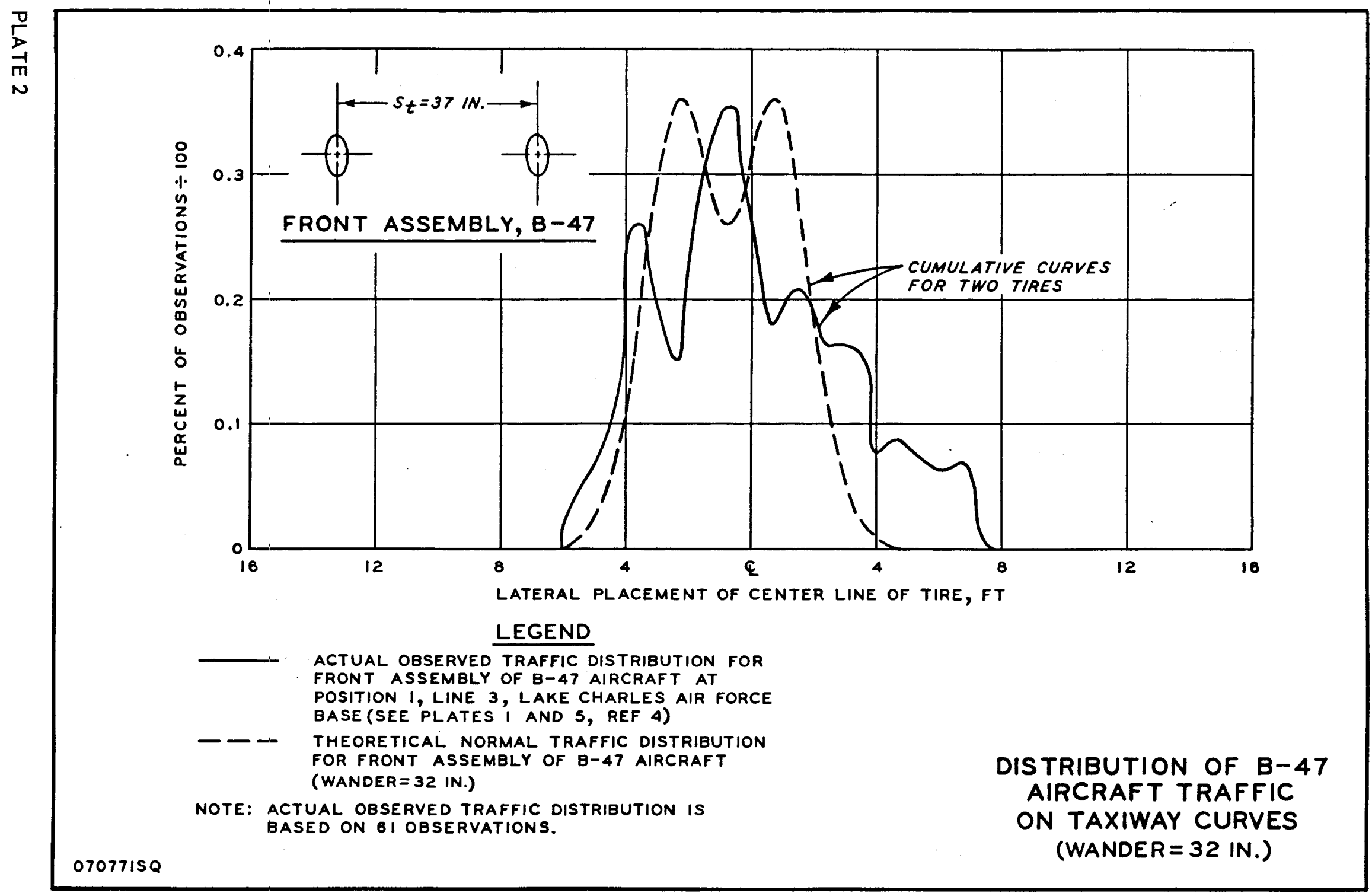




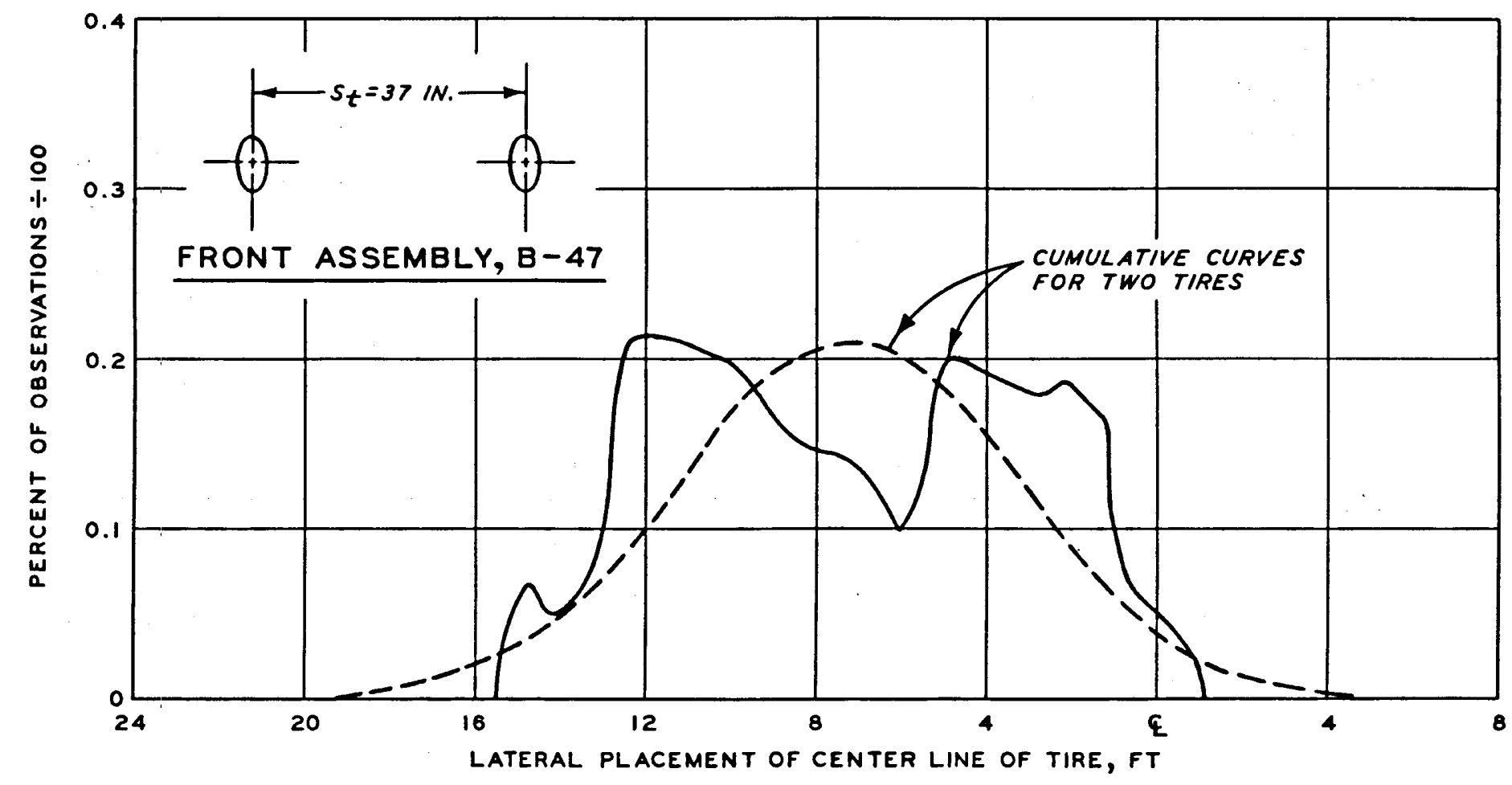

\section{LEGEND}

ACTUAL OBSERVED TRAFFIC DISTRIBUTION FOR

FRONT ASSEMBLY OF B-47 AIRCRAFT AT

POSITION 3, LINE 4, MaCDILL AIR FORCE

BASE (SEE PLATES 3 AND 5, REF 4)

- - THEORETICAL NORMAL TRAFFIC DISTRIBUTION

FOR FRONT ASSEMBLY OF B-47 AIRCRAFT (WANDER $=95$ IN.)

NOTE: ACTUAL OBSERVED TRAFFIC DISTRIBUTION IS BASED ON 21 OBSERVATIONS.

DISTRIBUTION OF $B-47$ AIRCRAF T TRAFFIC ON TAXIWAY CURVES (WANDER $=95$ IN.) 


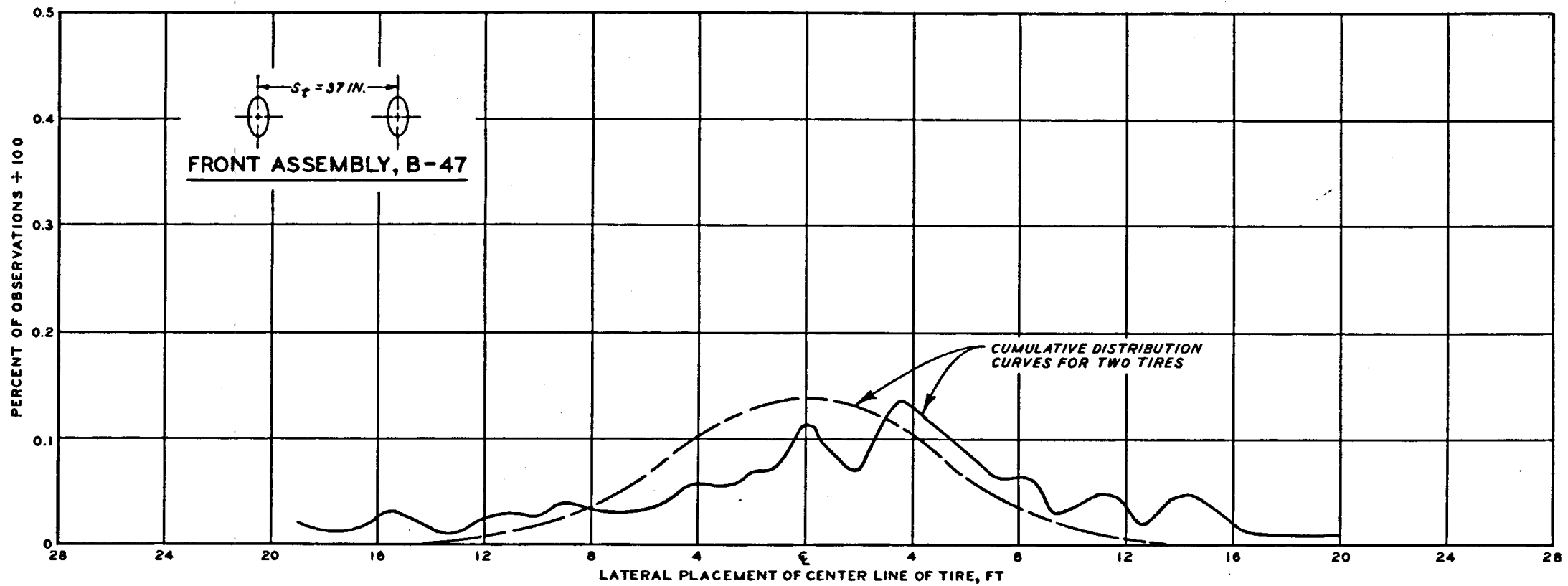

\section{LEGEND}

ACTUAL OBSERVED TRAFFIC DISTRIBUTION FOR FRONT

ASSEMBLY OF B-47 (SEE PLATE 2, REF S)

THEORETICAL NORMAL TRAFFIC DISTRIBUTION FOR

FRONT ASSEMBLY OF B -47 (WANDER $=150$ IN.)

NOTE: ACTUAL OBSERVED TRAFFIC DISTRIBUTION CURVE

IS BASED ON 253 OASERVATIONS MADE AT DYESS,

ALTUS, HOMESTEAD, AND MCCOY AIR FORCE BASES.

DISTRIBUTION OF B-47

AIRCRAFT TAKEOFF TRAFFIC

ALONG RUNWAYS

1000 FT FROM RUNWAY END 


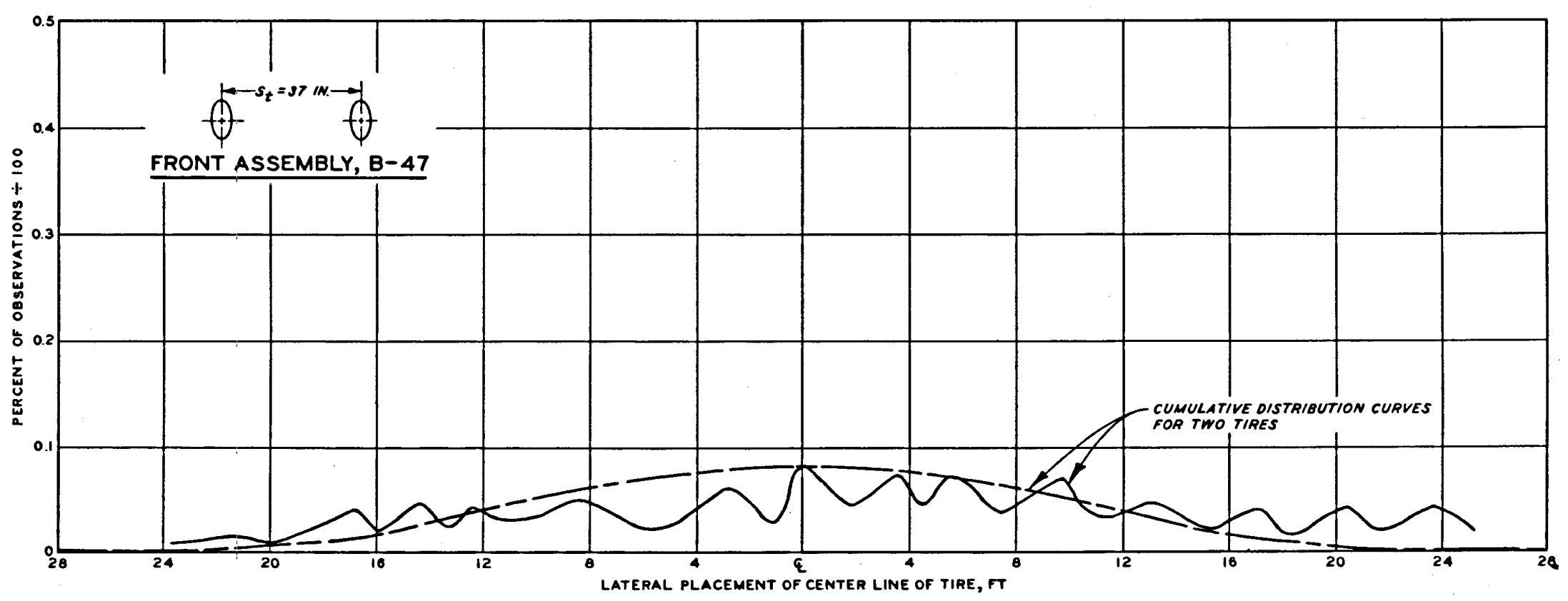

\section{LEGEND}

ACTUAL OBSERVED TRAFFIC DISTRIBUTION FOR FRONT ASSEMBLY OF B-47 (SEE PLATE 2, REF S)

THEORETICAL NORMAL TRAFFIC DISTRIBUTION FOR

NOTE: ACTUAL OBSERVED TRAFFIC DISTRIBUTION CURVE IS BASED ON 309 OBSERVATIONS MADE AT DYESS. ALTUS, HOMESTEAD, AND MCCOY AIR FORCE GASES. 


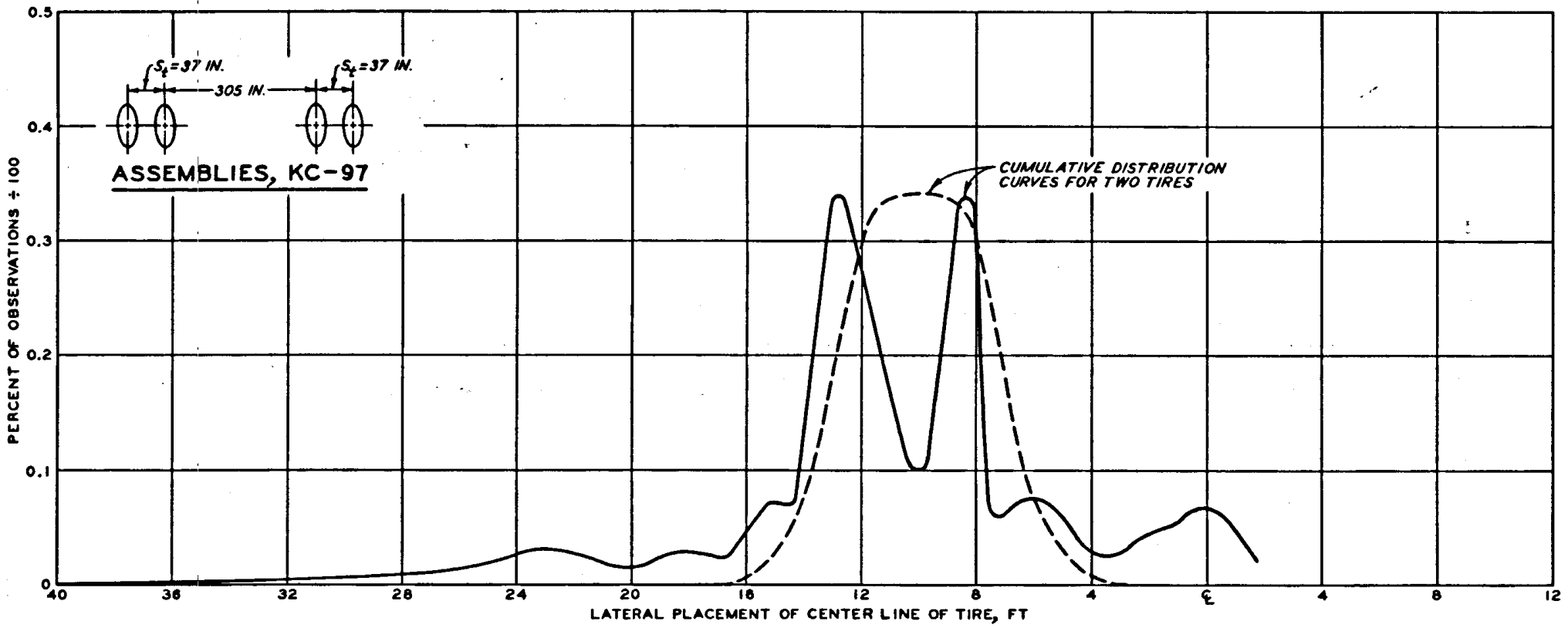

\section{LEGEND}

FOR LEFT ASSEMBLY OF KC-97 (SEE PLATE S, REF 5)

THEORETICAL NORMAL TRAFFIC OISTRIBUTION
FOR LEFT ASSEMBLY OF KC-97 (WANDER $=37$ IN.) NOTE: ACTUAL OBSERVED TRAFFIC DISTRIBUTION CURVE IS
BASED ONN 113 OBSERVATIONS MADE AT OYESS, ALTTU, HOMESTEAD, MeCOY, LORING, AND MadDILL AIR 


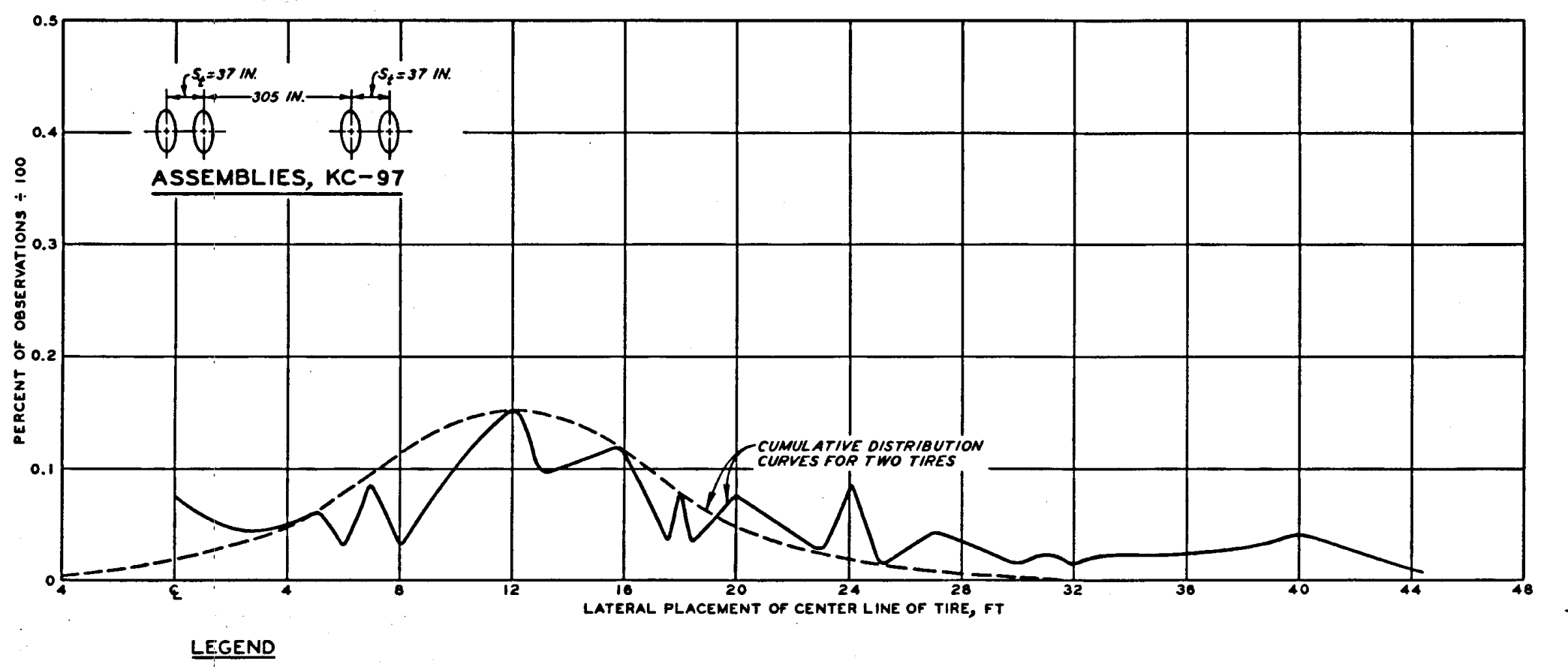

ACTUAL OQSERVED TRAFFIC DISTRIBUTION
FOR LEFT ASSEMBLY OF KC-97 (SEE PLATE 5, REF 5)

THEORETICAL NORMAL TRAFFIC OISTRIBUTION
FOR LEFT ASSEMELY OF KC-97 (WANDER $=130$ IN.)

NOTE: ACTUAL OBSERVED TRAFFIC DISTRIBUTION CURVE IS BASED ON OS OBSERVATIONS MADE AT DYESS, ALTUS, FORCE BASE'S. 


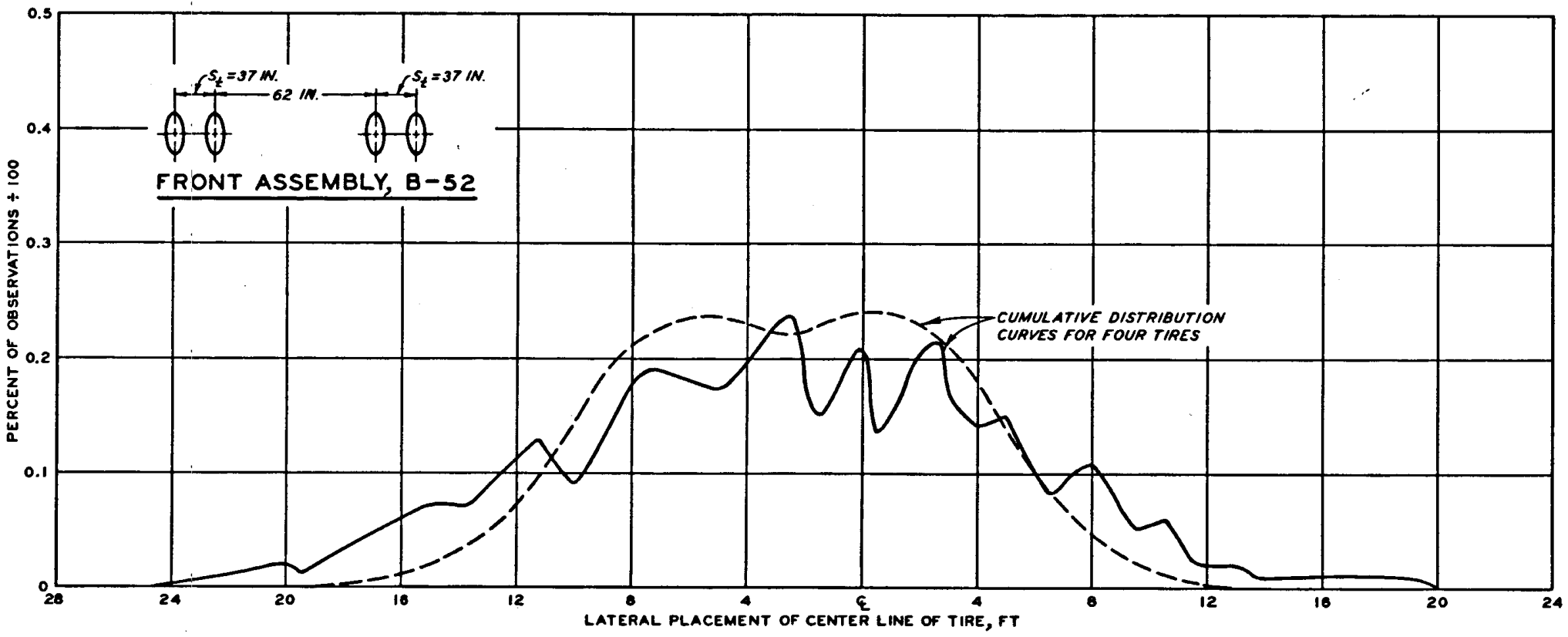

LEGEND

UTION FOR FRONT

ASSEMBLY OF B-52 (SEE PLATE 3, REF 5)

THEORETICAL NORMAL TRAFFIC DISTRIBUTION FOR FRONT

ASSEMBLY OF B-52 (WANDER $=87.5$ IN.)

NOTE: ACTUAL OBSERVED TRAFFIC DISTRIBUTION CURVE IS BASED ON 1 OO OSEREVATIONS MADE AT LORING
ANO CASTLE AIR FORCE BASES.

DISTRIBUTION OF B-52 AIRCRAFT TAKEOFF TRAFFIC ALONG RUNWAYS 


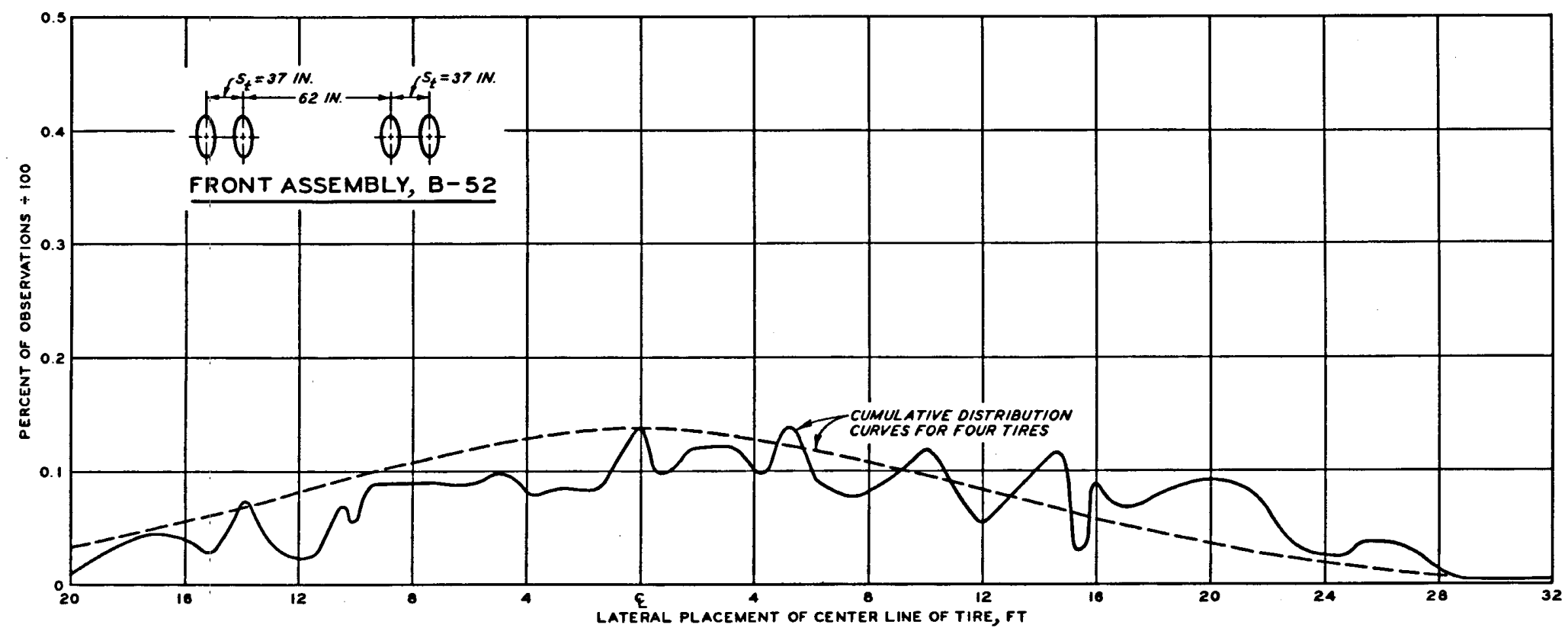

\section{LEGEND}

ACTUAL OBSERVED TRAFFIC DISTRIBUTION FOR FRONT

ASSEMBLY OF B-52 (SEE PLATE 3, REF 5)

THEORETICAL NORMAL TRAFFIC DISTRIBUTION FOR FRONT

ASSEMBLY OF B-52 (WANDER $=300 \mathrm{IN}$.)

NOTE: ACTUAL OBSERVED TRAFFIC DISTRIBUTION CURVE IS BASED ON IIO OBSERVATIONS MADE AT LORING AND CASTLE AIR FORCE BASES.

DISTRIBUTION OF B-52 AIRCRAFT LANDING TRAFFIC ALONG RUNWAYS 


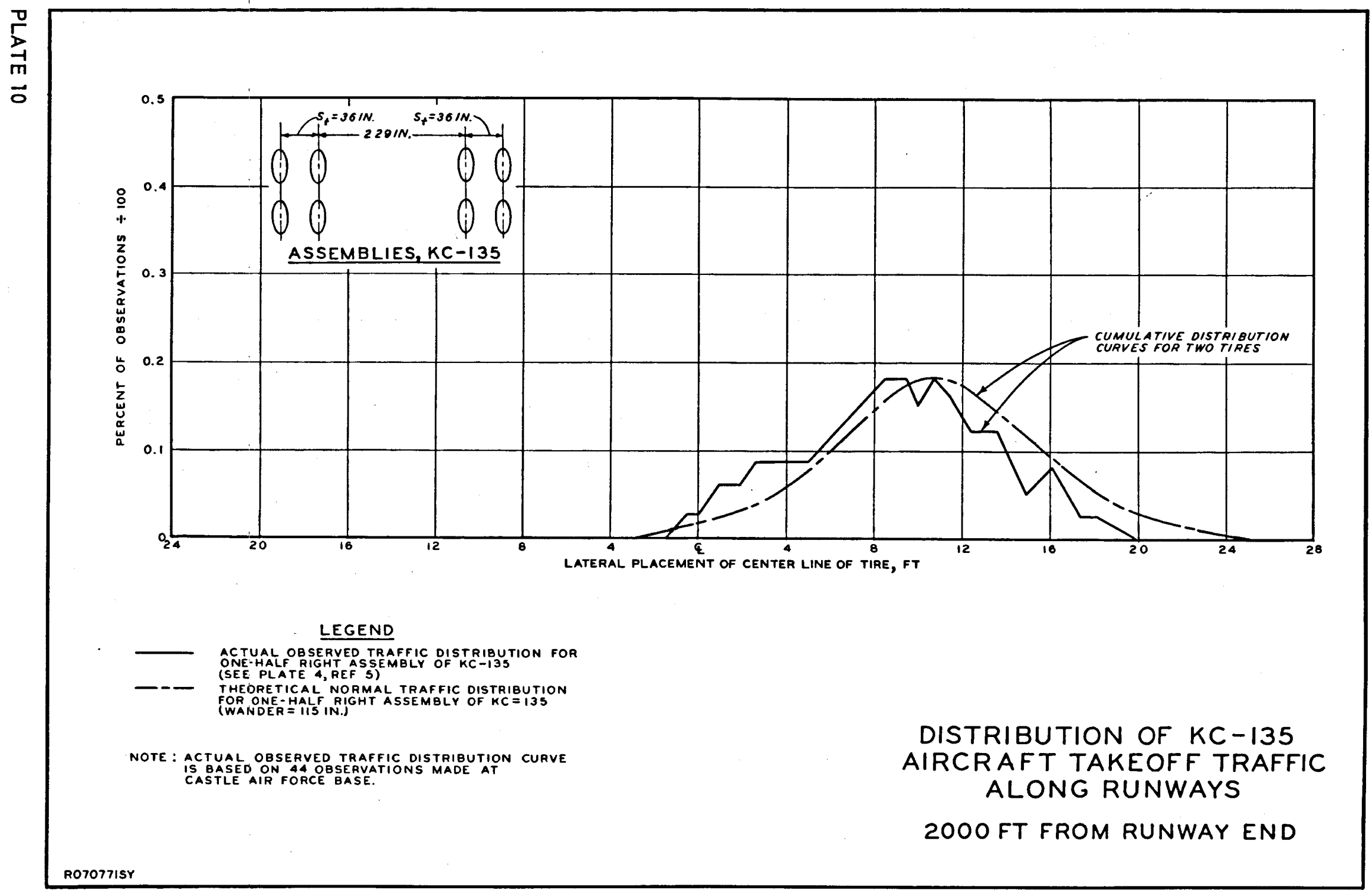




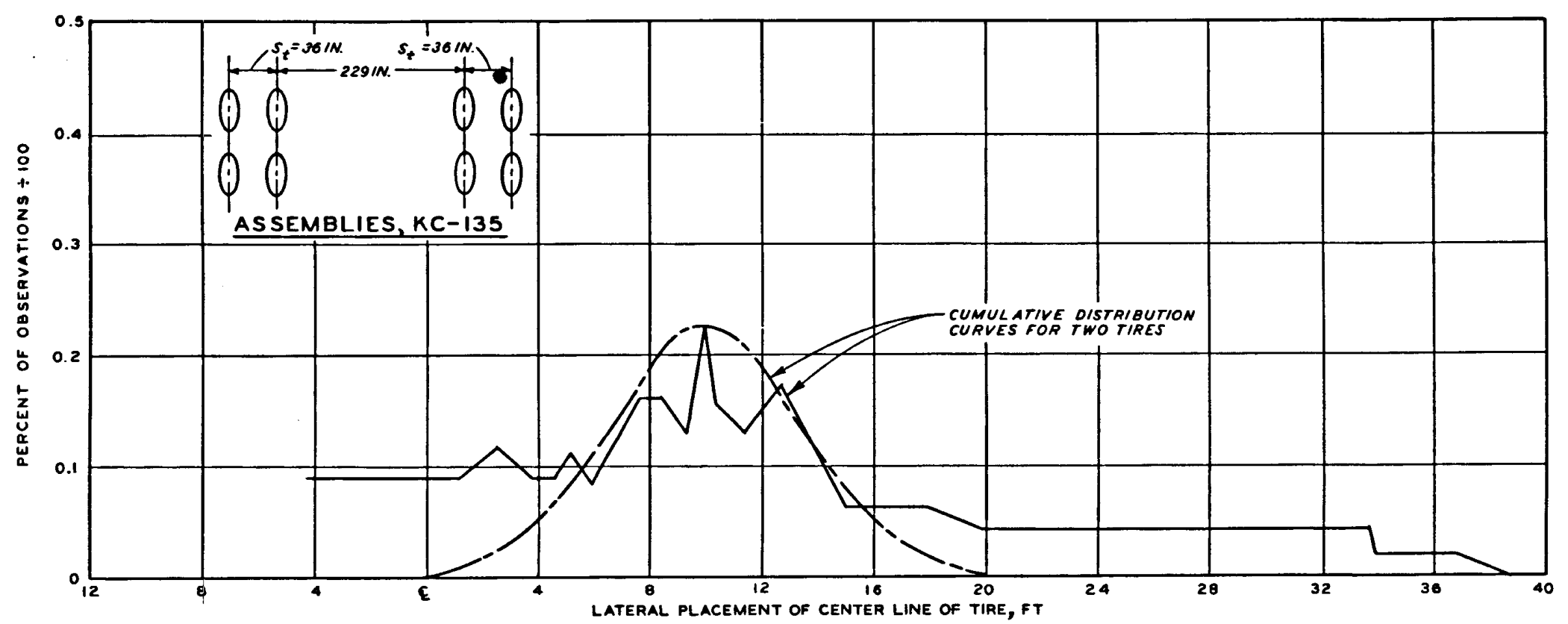

\section{LEGEND}

ACTUAL OBSERYED TRAFFIC DISTRIBUTION FOR ONE-HALF RIGHT ASSEMBLY OF KC-I35

(SEE PLATE 4, REF 5 )

THEORETICAL NORMAL TRAFFIC DISTRIBUTION (WANDER $=90$ IN.)
(WAN 
Unclassified

Security Classification

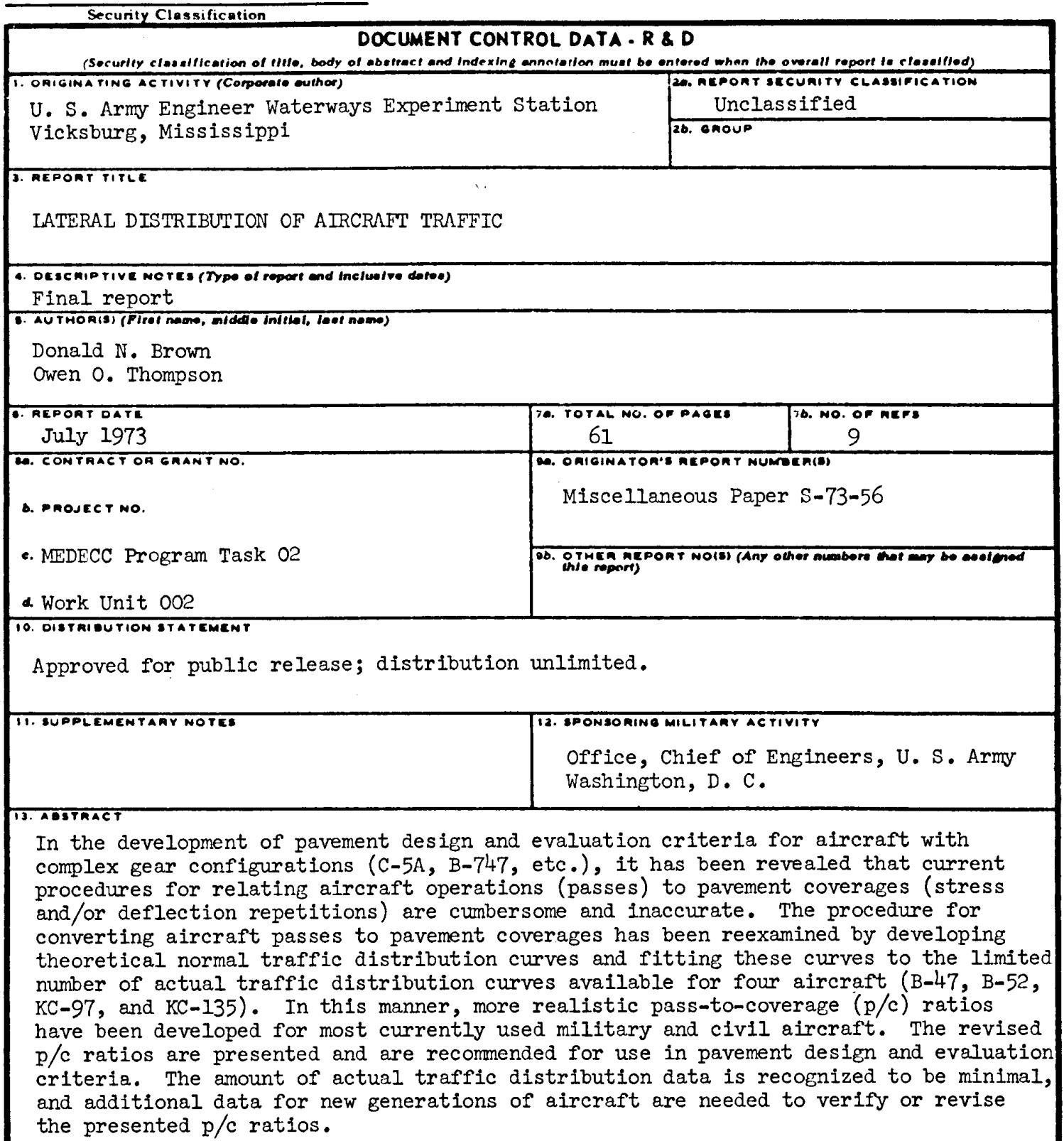


Unclassified

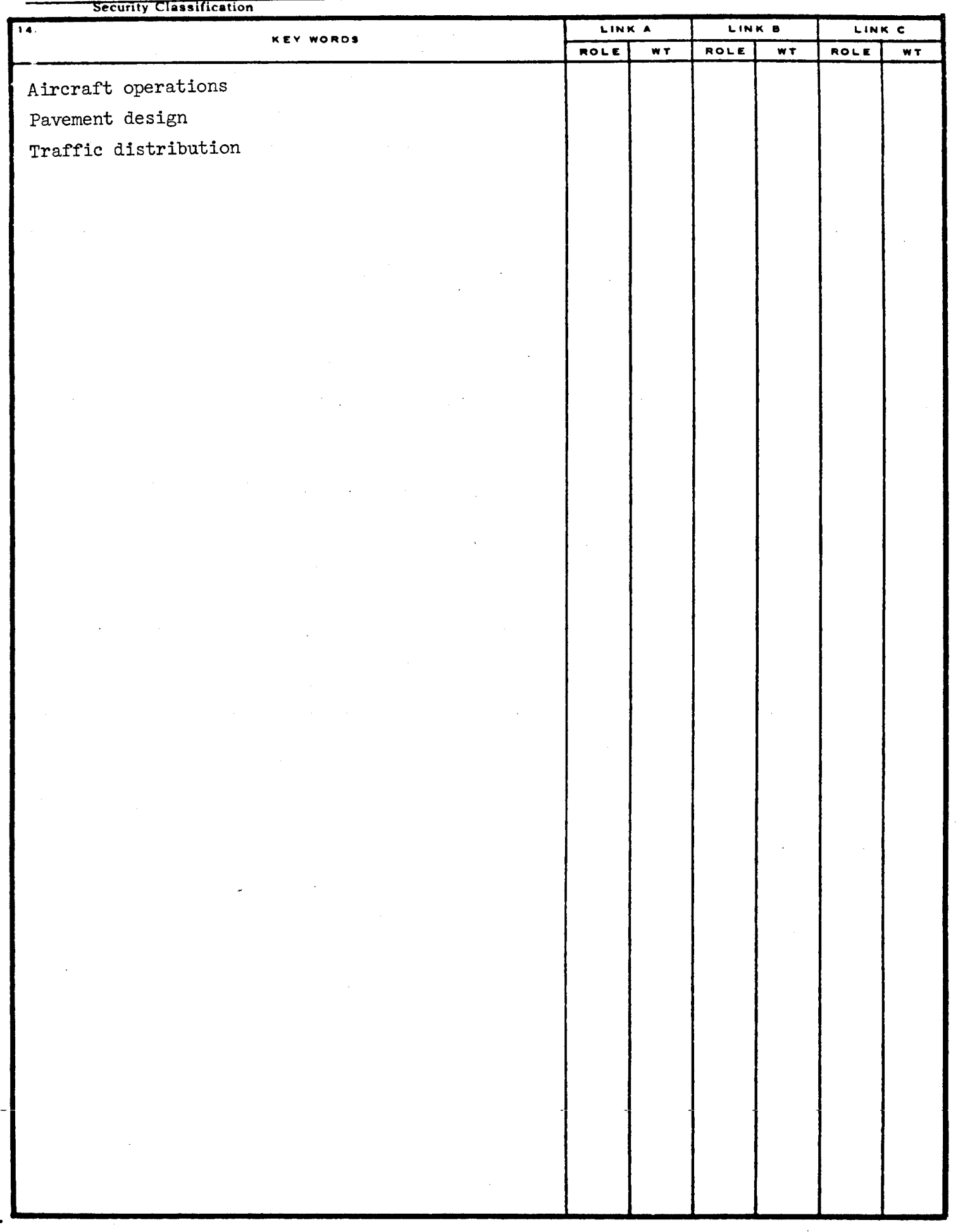

Unclassified

security Cteoelfication 